Supporting Information for

\title{
Phenol Reduces Nitrite to NO at Copper(II): Role of a Proton- Responsive Outer Coordination Sphere in Phenol Oxidation
}

\author{
Aditesh Mondal, ${ }^{\dagger}$ Kiran P. Reddy,${ }^{\dagger}$ Jeffery A. Bertke, ${ }^{\ddagger}$ and Subrata Kundu* ${ }^{* \dagger}$ \\ †School of Chemistry, Indian Institute of Science Education and Research \\ Thiruvananthapuram (IISER-TVM), Thiruvananthapuram 695551, India \\ "Department of Chemistry, Georgetown University, Box 571227-1227, Washington, \\ D. C. 20057 , United States
}

*Corresponding author email: $\underline{\text { skundu@,iisertvm.ac.in, skundu.chem@gmail.com }}$

\section{Table of Contents}

1. General Considerations and Physical Methods $\quad$ S2

2. Materials S4

3. Synthesis and Characterization of $[\mathrm{mC}] \mathrm{Cu}\left(\kappa^{2}-\mathrm{O}_{2} \mathrm{~N}\right)\left(\mathrm{ClO}_{4}\right)(\mathbf{1 a}) \quad$ S5

4. Synthesis and Characterization of $[\mathrm{mC}] \mathrm{Zn}\left(\kappa^{2}-\mathrm{O}_{2} \mathrm{~N}\right)\left(\mathrm{ClO}_{4}\right)(\mathbf{1 b}) \quad \mathbf{S 6}$

5. Synthesis and Characterization of $[\mathrm{mCH}] \mathrm{CuCl}\left(\mathrm{ClO}_{4}\right)_{2}(2) \quad \mathbf{S 7}$

6. Synthesis and Characterization of $[\mathrm{mCH}] \mathrm{Cu}\left(\kappa^{2}-\mathrm{O}_{2} \mathrm{~N}\right)\left(\mathrm{ClO}_{4}\right)_{2}(3) \quad \mathbf{S 8}$

7. Reactions of $[\mathrm{mC}] \mathrm{Cu}\left(\kappa^{2}-\mathrm{O}_{2} \mathrm{~N}\right)\left(\mathrm{ClO}_{4}\right)(\mathbf{1 a})$ with substituted phenols $\quad$ S9

8. Reactions of $[\mathrm{mC}] \mathrm{Zn}\left(\kappa^{2}-\mathrm{O}_{2} \mathrm{~N}\right)\left(\mathrm{ClO}_{4}\right)(\mathbf{1 b})$ with 2,4-di-tert-butylphenol $\quad \mathbf{S 1 1}$

9. Reactions of $[\mathrm{mCH}] \mathrm{Cu}\left(\kappa^{2}-\mathrm{O}_{2} \mathrm{~N}\right)\left(\mathrm{ClO}_{4}\right)_{2}$ (3) with 2,4-di-tert-butylphenol $\quad \mathbf{S 1 2}$

10. Qualitative NO Trapping by $(\mathrm{dtc})_{2} \mathrm{Fe}^{\mathrm{II}}$ Complex $\quad \mathbf{S 1 5}$

11. Figures and Tables $\quad$ S16

12. References $\mathbf{S 4 3}$ 


\section{General Considerations and Physical Methods}

The preparation and handling of air-sensitive chemicals were performed under dry argon/ nitrogen atmosphere by utilizing standard Schlenk techniques and/or a MBraun Glovebox with $<0.1 \mathrm{ppm}_{2}$ and $\mathrm{H}_{2} \mathrm{O}$.

CHNS Analyses: Elemental analyses were performed on an Elementar Vario Micro Cube CHNS analyzer.

NMR Spectroscopic Studies: ${ }^{1} \mathrm{H}$ and ${ }^{13} \mathrm{C}$ NMR spectra were recorded on a Bruker Advance III $500 \mathrm{MHz}$ NMR spectrometer at room temperature unless otherwise noted. The chemical shift $(\delta)$ values are expressed in ppm relative to tetramethylsilane, whereas the residual ${ }^{1} \mathrm{H},{ }^{13} \mathrm{C}$ signals of the deuterated solvent served as an internal standard.

EPR Spectroscopic Studies: EPR spectra were collected at SAIF, IIT Bombay on a JEOL continuous wave spectrometer JES-FA200 equipped with an X-band Gunn oscillator bridge, a cylindrical mode cavity, and a liquid nitrogen cryostat. EPR measurements were performed in sealed quartz tubes.

UV-vis Spectroscopic Studies: UV-vis spectra were recorded on an Agilent 8454 Diode Array spectrometer equipped with a magnetic stirrer and Unisoku USP-203 cryostats for variable temperature $\left(-105{ }^{\circ} \mathrm{C}\right.$ to $\left.90{ }^{\circ} \mathrm{C}\right)$ experiments. Solutions for UV-vis analysis were prepared freshly by dissolving analytically pure compounds in anhydrous solvents. The molar extinction coefficients of different isolated complexes were determined from the Beer's law plot (absorbance vs concentration) with at least four different concentrations. Details of the reaction kinetics appear in Sections 7.2 and 9.2.

Infrared (IR) Spectroscopic Studies: IR spectra (with the spectral resolution of 4 $\mathrm{cm}^{-1}$ ) were collected on a Shimadzu IRPrestige-21 FTIR spectrometer by using KBr pellet method. The intensities of the vibrational bands are abbreviated as follows: $\mathrm{s}=$ strong, $\mathrm{m}=$ medium, $\mathrm{w}=$ weak, $\mathrm{vw}=$ very weak, and $\mathrm{br}=$ broad.

Powder X-ray Diffraction (PXRD) Analyses: PXRD data were collected employing an X'pert PRO (PANalytics) powder diffractometer equipped with a $\mathrm{Cu} K_{\alpha}$ ( $\lambda$ $=1.5405 \AA$ ) radiation source. 
Single Crystal X-ray Diffraction (SCXRD) Analysis: Single crystals of each compound 1a (CCDC 1960186), 1b (CCDC 1960187), 2 (CCDC 1960188), and 3 (CCDC 1960189) were mounted under mineral oil on a glass capillary. Data for all compounds were collected at $150 \mathrm{~K}$, on a Bruker Kappa diffractometer equipped with an APEXII CCD detector and Mo fine focus sealed tube source. All data were collected by employing graphite monochromated $\operatorname{Mo} K_{\alpha}$ radiation $(\lambda=0.7107 \AA)$ and the data sets were processed using APEX II software. Integration of the data sets were carried out with the Bruker SAINT program. Structure solutions were performed using the SHELXTL/PC suite. ${ }^{\text {S1 }}$ Intensities were corrected for Lorentz and polarization effects and an empirical absorption correction was applied using Blessing's method as incorporated into the program SADABS. ${ }^{\text {S2 }}$ Non-hydrogen atoms were refined with anisotropic thermal parameters. All amine and water hydrogen atoms were located in the difference map, with the exception of the disordered amine (N2/N2B) in 2. Remaining hydrogen atoms were included in idealized positions. The molecular structures were rendered using MERCURY 3.10.3 software. ${ }^{\mathrm{S} 3}$

Gas Chromatography - Mass Spectrometric (GC-MS) Analyses: GC-MS analyses of the reaction mixtures were performed on a SHIMADZU GCMS-QP2010 PLUS spectrometer. Hamilton microliter syringe was used to inject $1.0 \mu \mathrm{L}$ of the sample for GC-MS analysis. Identification of the organic products were carried out by comparing their retention times, electron ionization (EI) mass spectra, and NMR spectra with those of the authentic and/or previously reported compounds.

MALDI-TOF Spectrometric Analyses: MALDI data were collected on a Bruker UltrafleXtreme MALDI-TOF spectrometer using 2,5-dihydroxy benzoic acid (DHB) as the matrix.

Electrospray Ionization - Mass Spectrometric (ESI-MS) Analyses: ESI-MS data were recorded on a Thermo Scientific Q Exactive Mass spectrometer employing electrospray ionization technique. 


\section{Materials}

All chemicals were purchased from standard vendors (e.g. Sigma-Aldrich, Spectrochem, Strem Chemicals, TCI) and used without further purification unless

otherwise mentioned. Molecular sieves (4A, 4-8 mesh beads) were activated in vacuo at $220^{\circ} \mathrm{C}$ for $24 \mathrm{~h}$. Anhydrous solvents were sparged with nitrogen and stored over activated molecular sieves under nitrogen atmosphere.

The heteroditopic cryptand (mC), ${ }^{\mathrm{S} 4}$ O-deuterated 2,4-di-tert-butylphenol $(2,4$ DTBP-OD / 2,4- $\left.{ }^{t} \mathrm{Bu}_{2} \mathrm{C}_{6} \mathrm{H}_{3} \mathrm{OD}\right)$, and O-deuterated 4-methoxyphenol (4- $\left.\mathrm{MeOC}_{6} \mathrm{H}_{4} \mathrm{OD}\right){ }^{\mathrm{S} 5}$ were synthesized and characterized according to the literature procedure. Disappearance of the $\mathrm{OH}$-proton resonance in the ${ }^{1} \mathrm{H} \mathrm{NMR}$ (in $\mathrm{CDCl}_{3}$ ) spectrum of the O-deuterated phenol confirmed $>99 \%$ O-deuteration of the phenol.

Caution! While we did not encounter any problem, metal perchlorate salts/complexes with organic ligands are potentially explosive. Hence, these complexes should be prepared and handled in small quantities at a time. 


\section{Synthesis and Characterization of $[\mathrm{mC}] \mathrm{Cu}\left(\kappa^{2}-\mathrm{O}_{2} \mathrm{~N}\right)\left(\mathrm{ClO}_{4}\right)(1 \mathrm{a})$}

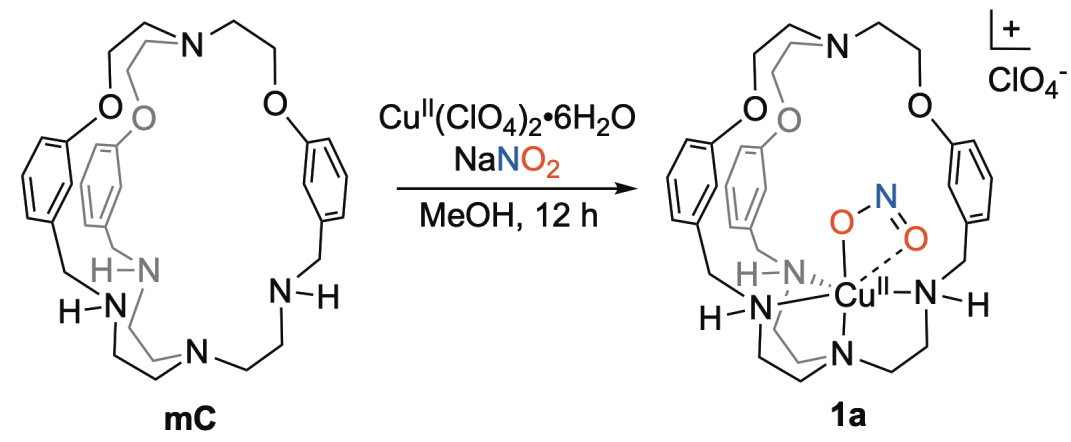

Scheme S1. Synthesis of 1a.

To a solution of cryptand $\mathbf{m C}(0.300 \mathrm{~g}, 0.536 \mathrm{mmol})$ in methanol $(\sim 6 \mathrm{~mL})$, a solution of copper(II) perchlorate hexahydrate $\mathrm{Cu}\left(\mathrm{ClO}_{4}\right)_{2} \cdot 6 \mathrm{H}_{2} \mathrm{O}(0.199 \mathrm{~g}, 0.536 \mathrm{mmol})$ and $\mathrm{NaNO}_{2}(0.037 \mathrm{~g}, 0.536 \mathrm{mmol})$ in methanol $(\sim 5 \mathrm{~mL})$ was added dropwise and the reaction mixture was stirred at room temperature. After stirring for $12 \mathrm{~h}$, the reaction mixture was filtered to isolate a bluish-green residue, which was washed with methanol, diethyl ether and dried under vacuum to yield a bluish-green powder of $1 \mathbf{a}(0.345 \mathrm{~g}, 0.449 \mathrm{mmol})$ in $84 \%$ yield.

Crystals suitable for single crystal X-ray crystallography were grown from slow evaporation of a solution of $\mathbf{1 a}$ in acetonitrile (Figure S1). Anal. \% Calcd for $[\mathrm{mC}] \mathrm{Cu}\left(\kappa^{2}-\right.$ $\left.\mathrm{O}_{2} \mathrm{~N}\right)\left(\mathrm{ClO}_{4}\right)(1 \mathrm{a}) \mathrm{C}_{33} \mathrm{H}_{45} \mathrm{~N}_{6} \mathrm{O}_{9} \mathrm{CuCl}: \mathrm{C}, 51.56 ; \mathrm{H}, 5.90 ; \mathrm{N}, 10.93$. Found: C, 51.62; H, 5.88; $\mathrm{N}, 11.16$. UV-Vis (Acetonitrile, $\left.25^{\circ} \mathrm{C}\right): \lambda_{\max } / \mathrm{nm}\left(\varepsilon / \mathrm{M}^{-1} \mathrm{~cm}^{-1}\right)=380(675)$ and 670 (190) (Figure S2). X-band EPR spectrum (Acetonitrile, $77 \mathrm{~K}$ ) of $[\mathrm{mC}] \mathrm{Cu}\left(\kappa^{2}-\mathrm{O}_{2} \mathrm{~N}\right)\left(\mathrm{ClO}_{4}\right)(\mathbf{1 a})$ confirms the presence of $S=1 / 2 \mathrm{~d}^{9} \mathrm{Cu}^{\mathrm{II}}$ site (Figure S3). FTIR (KBr pellet): 3516 (m, br), 3251 (s), 2868 (s), 1585 (s), 1485 (s), 1448 (s), 1352 (s, NO $2^{-}$), 1265 (s), 1157 (s), 1097 (s), 1066 (s), 1024 (s), 989 (s), 925 (m), 842 (m, NO$\left.{ }^{-}\right), 788$ (s), 748 (m), 700 (m), 623 (s) (Figure S4). 


\section{Synthesis and Characterization of $[\mathrm{mC}] \mathrm{Zn}\left(\kappa^{2}-\mathrm{O}_{2} \mathrm{~N}\right)\left(\mathrm{ClO}_{4}\right)(1 \mathrm{~b})$}

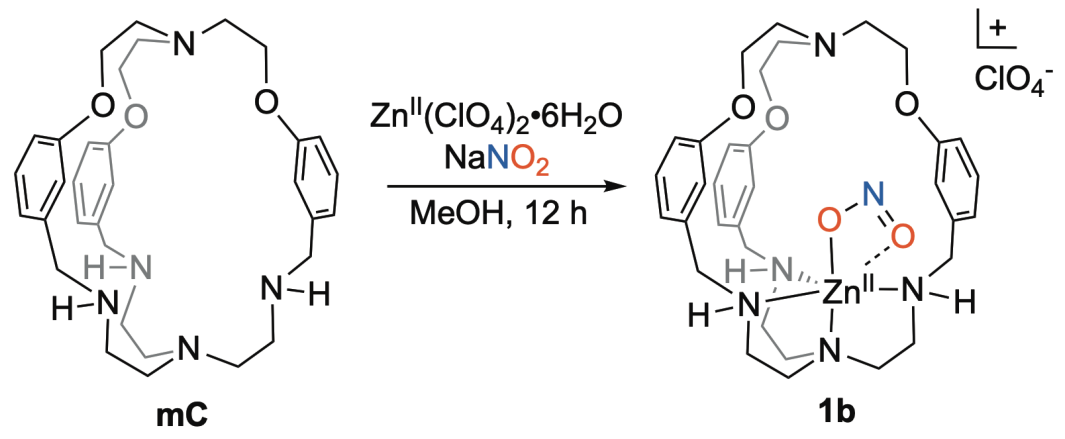

Scheme S2. Synthesis of $\mathbf{1 b .}$

To a solution of cryptand $\mathbf{m C}(0.200 \mathrm{~g}, 0.357 \mathrm{mmol})$ in methanol $(\sim 5 \mathrm{~mL})$, a solution of zinc(II) perchlorate hexahydrate $\mathrm{Zn}\left(\mathrm{ClO}_{4}\right)_{2} \cdot 6 \mathrm{H}_{2} \mathrm{O}(0.133 \mathrm{~g}, 0.357 \mathrm{mmol})$ and $\mathrm{NaNO}_{2}(0.025 \mathrm{~g}, 0.357 \mathrm{mmol})$ in methanol $(\sim 4 \mathrm{~mL})$ was added dropwise and the reaction mixture was stirred at room temperature. After stirring for $12 \mathrm{~h}$, the reaction mixture was filtered to isolate a white residue, which was washed with methanol, diethyl ether and dried under vacuum to yield a white powder of $\mathbf{1 b}(0.215 \mathrm{~g}, 0.279 \mathrm{mmol})$ in $78 \%$ yield.

Crystals suitable for single crystal X-ray crystallography were grown from slow evaporation of a solution of $\mathbf{1 b}$ in acetonitrile (Figure S5). Anal. \% Calcd for $[\mathrm{mC}] \mathrm{Zn}\left(\kappa^{2}-\right.$ $\left.\mathrm{O}_{2} \mathrm{~N}\right)\left(\mathrm{ClO}_{4}\right) \cdot 0.3 \mathrm{H}_{2} \mathrm{O}\left(\mathbf{1 b} \cdot 0.3 \mathrm{H}_{2} \mathrm{O}\right) \mathrm{C}_{33} \mathrm{H}_{45} \mathrm{~N}_{6} \mathrm{O}_{9} \mathrm{ZnCl} \cdot 0.3 \mathrm{H}_{2} \mathrm{O}: \mathrm{C}, 51.08 ; \mathrm{H}, 5.92 ; \mathrm{N}, 10.83$. Found: C, 50.91; H, 5.79; N, 11.00. FTIR (KBr pellet): 3232 (s), 2918 (s), 2868 (s), 2835 (s), 1587 (s), 1485 (s), 1448 (s), 1325 (m), 1300 (m), 1265 (w), 1163 (s), 1097 (m), 1062 (s), $1024(\mathrm{~s}), 995(\mathrm{~m}), 925(\mathrm{~m}), 885(\mathrm{~m}), 844(\mathrm{~m}), 790(\mathrm{~s}), 748(\mathrm{~m}), 700(\mathrm{~m}), 623$ (s) (Figure S6). 


\section{Synthesis and Characterization of $[\mathrm{mCH}] \mathrm{CuCl}\left(\mathrm{ClO}_{4}\right)_{2}(2)$}

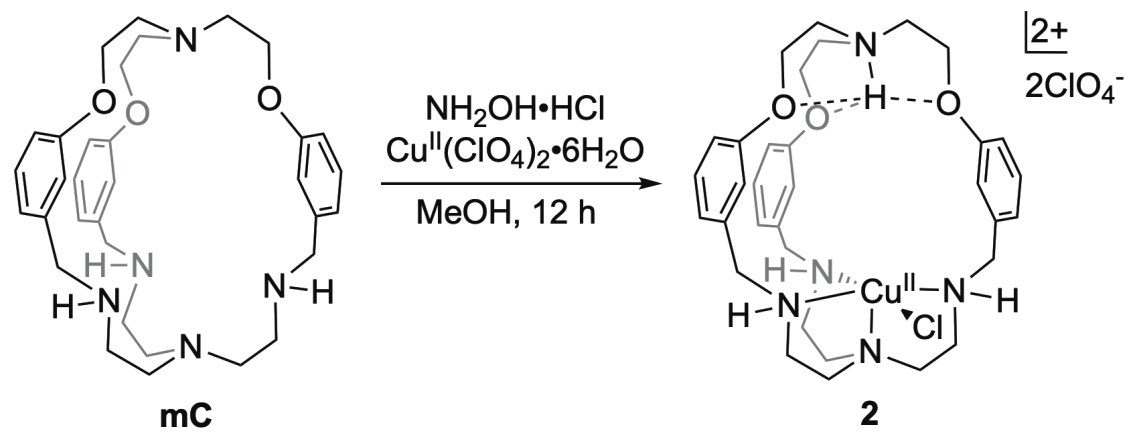

Scheme S3. Synthesis of 2.

A solution of cryptand $\mathbf{m C}(0.300 \mathrm{~g}, 0.536 \mathrm{mmol})$ in methanol $(\sim 6 \mathrm{~mL})$ was treated with $\mathrm{NH}_{2} \mathrm{OH} \cdot \mathrm{HCl}$ and the resultant solution was stirred for $1 \mathrm{~h}$. Subsequently, a solution of copper(II) perchlorate hexahydrate $\mathrm{Cu}\left(\mathrm{ClO}_{4}\right)_{2} \cdot 6 \mathrm{H}_{2} \mathrm{O}(0.199 \mathrm{~g}, 0.536 \mathrm{mmol})$ in methanol $(\sim 5 \mathrm{~mL})$ was added dropwise and the reaction mixture was stirred at room temperature. After stirring for $12 \mathrm{~h}$, the reaction mixture was filtered to isolate a bright green residue, which was washed with methanol, diethyl ether and dried under vacuum to yield a bright green powder of $2(0.330 \mathrm{~g}, 0.384 \mathrm{mmol})$ in $72 \%$ yield.

Crystals suitable for single crystal X-ray crystallography were grown from slow evaporation of a solution of $\mathbf{2}$ in acetonitrile (Figure S7). Anal. \% Calcd for $[\mathrm{mCH}] \mathrm{CuCl}\left(\mathrm{ClO}_{4}\right)_{2}(2) \mathrm{C}_{33} \mathrm{H}_{46} \mathrm{~N}_{5} \mathrm{O}_{11} \mathrm{CuCl}_{3}: \mathrm{C}, 46.16 ; \mathrm{H}, 5.40 ; \mathrm{N}, 8.16$. Found: $\mathrm{C}, 45.85 ;$ $\mathrm{H}, 5.19 ; \mathrm{N}, 8.21$. UV-Vis (Acetonitrile, $25^{\circ} \mathrm{C}$ ): $\lambda_{\max } / \mathrm{nm}\left(\varepsilon / \mathrm{M}^{-1} \mathrm{~cm}^{-1}\right)=660$ (190) (Figure S8). X-band EPR spectrum (Acetonitrile, $77 \mathrm{~K}$ ) of $[\mathrm{mCH}] \mathrm{CuCl}\left(\mathrm{ClO}_{4}\right)_{2}$ (2) confirms the presence of $S=1 / 2 \mathrm{~d}^{9} \mathrm{Cu}^{\mathrm{II}}$ site (Figure S9). FTIR (KBr pellet): 3435 (s, br), 3248 (s), 3207 (s), 3159 (s), 2926 (s), 2877 (s), 1614 (s), 1587 (s), 1487 (s), 1458 (s), 1394 (m), 1300 (s), 1259 (s), 1170 (s, $\left.\mathrm{ClO}_{4}{ }^{-}\right), 1089$ (s, $\mathrm{ClO}_{4}^{-}$), 1014 (s), 877 (m), 758 (s), 754 (m), 694 (m), 624 (s) (Figure S10). 


\section{Synthesis and Characterization of $[\mathrm{mCH}] \mathrm{Cu}\left(\kappa^{2}-\mathrm{O}_{2} \mathrm{~N}\right)\left(\mathrm{ClO}_{4}\right)_{2}(3)$}

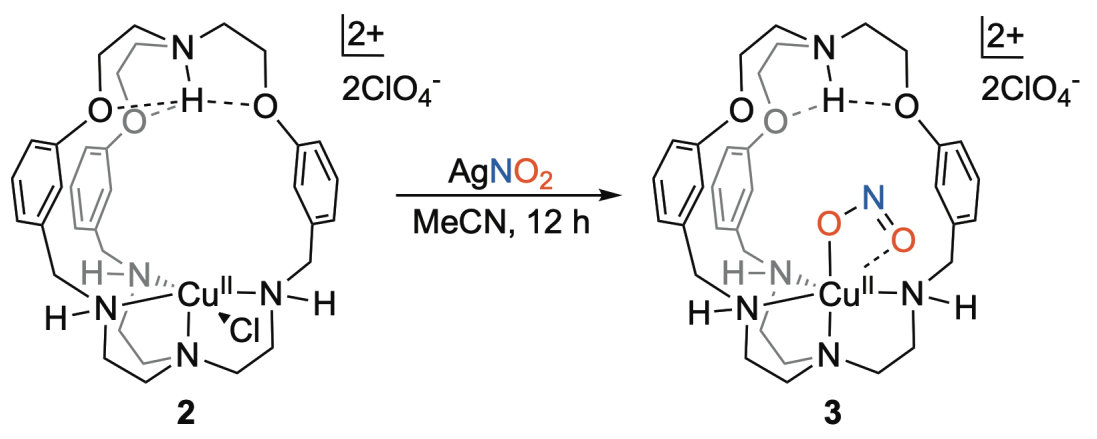

Scheme S4. Synthesis of 3 .

To a solution of $[\mathrm{mCH}] \mathrm{CuCl}\left(\mathrm{ClO}_{4}\right)_{2}(2)(0.300 \mathrm{~g}, 0.349 \mathrm{mmol})$ in anhydrous acetonitrile $(\sim 6 \mathrm{~mL}), \mathrm{AgNO}_{2}(0.054 \mathrm{~g}, 0.349 \mathrm{mmol})$ was added and stirred at room temperature. The color of the resultant reaction mixture changed to darker green. After stirring for $12 \mathrm{~h}$, the reaction mixture was filtered to remove the insoluble material and the green filtrate was collected. Evaporation of solvent from the filtrate afforded a dark green powder of the desired complex $3(0.286 \mathrm{~g}, 0.329 \mathrm{mmol})$ in $94 \%$ yield.

Crystals suitable for single crystal X-ray crystallography were grown from slow evaporation of a solution of 3 in acetonitrile (Figure S11). Anal. \% Calcd for $[\mathrm{mCH}] \mathrm{Cu}\left(\kappa^{2}-\right.$ $\left.\mathrm{O}_{2} \mathrm{~N}\right)\left(\mathrm{ClO}_{4}\right)_{2} \cdot 0.35 \mathrm{CH}_{3} \mathrm{CN}\left(3 \cdot 0.35 \mathrm{CH}_{3} \mathrm{CN}\right) \mathrm{C}_{33} \mathrm{H}_{46} \mathrm{~N}_{6} \mathrm{O}_{13} \mathrm{CuCl}_{2} \cdot 0.35 \mathrm{CH}_{3} \mathrm{CN}: \mathrm{C}, 45.81 ; \mathrm{H}$, 5.37; N, 10.07. Found: C, 45.41; H, 5.31; N, 10.44. UV-Vis (Acetonitrile, $25^{\circ} \mathrm{C}$ ): $\lambda_{\max } / \mathrm{nm}$ $\left(\varepsilon / \mathrm{M}^{-1} \mathrm{~cm}^{-1}\right)=660(180)$ (Figure S12). X-band EPR spectrum (Acetonitrile, $\left.77 \mathrm{~K}\right)$ of $[\mathrm{mCH}] \mathrm{Cu}\left(\kappa^{2}-\mathrm{O}_{2} \mathrm{~N}\right)\left(\mathrm{ClO}_{4}\right)_{2}(3)$ confirms the presence of $S=1 / 2 \mathrm{~d}^{9} \mathrm{Cu}^{\mathrm{II}}$ site (Figure S13). FTIR (KBr pellet): 3587 (m, br), 3138 (m), 2879 (m), 1612 (m), 1587 (s), 1487 (m), 1454 (s), $1388(\mathrm{~m}), 1263$ (s), 1169 (m), 1091 (s), 786 (m), 696 (m), 624 (s) (Figure S14). 


\section{Reactions of $[\mathrm{mC}] \mathrm{Cu}\left(\kappa^{2}-\mathrm{O}_{2} \mathrm{~N}\right)\left(\mathrm{ClO}_{4}\right)(1 \mathrm{a})$ with substituted phenols}

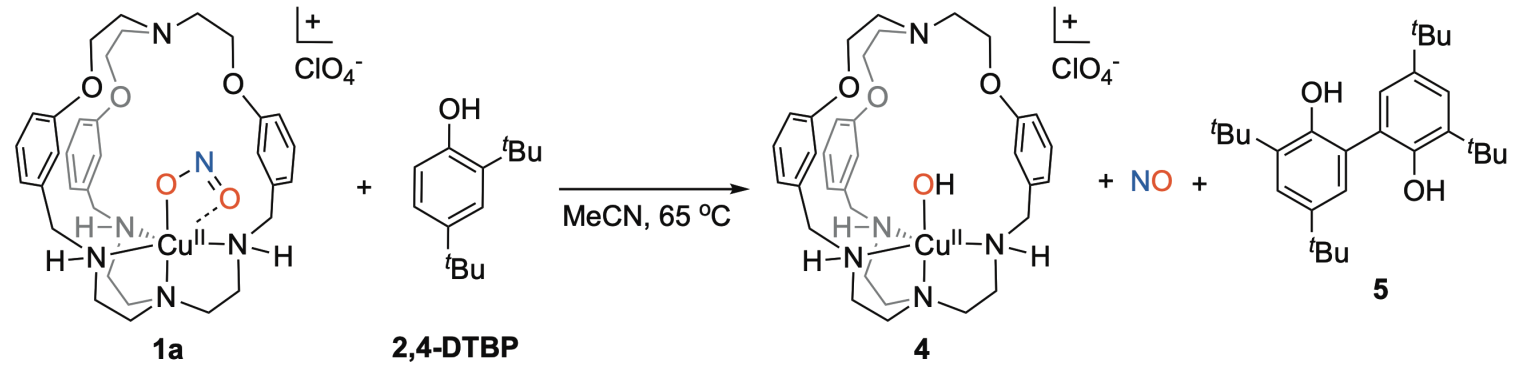

Scheme S5. Reaction of 1a with 2,4-DTBP.

\subsection{Product analysis for the reaction of 1 a with $2,4-D T B P$}

A solution of $[\mathrm{mC}] \mathrm{Cu}\left(\kappa^{2}-\mathrm{O}_{2} \mathrm{~N}\right)\left(\mathrm{ClO}_{4}\right)(\mathbf{1 a})(0.100 \mathrm{~g}, 0.130 \mathrm{mmol})$ in anhydrous acetonitrile $(\sim 8 \mathrm{~mL})$ was transferred to a heavy-wall pressure vessel inside a glovebox. One equivalent of 2,4-di-tert-butylphenol (2,4-DTBP) $(0.027 \mathrm{~g}, 0.130 \mathrm{mmol})$ was added to the solution of $1 \mathrm{a}$ and the resultant reaction mixture warmed at $65^{\circ} \mathrm{C}$ until the initial greenish color turns to yellowish. The resultant reaction mixture was dried in vacuo and hexane was added for extracting the organic products and precipitating the yellowish $\mathrm{Cu}$ product 4 . The yellowish residue 4 was separated by filtration and washed with hexane for several times and dried in vacuo to afford $[\mathrm{mC}] \mathrm{Cu}(\mathrm{OH})\left(\mathrm{ClO}_{4}\right)(4)$ in $87 \%$ yield. The spectroscopic and analytical (Mass, EPR, and elemental analysis) evidences support the presence of $\{[\mathrm{mC}] \mathrm{Cu}(\mathrm{OH})\}^{+}$in the reaction mixture obtained from the reaction of $\mathbf{1 a}$ and 2,4-DTBP (vide infra). However, several attempts to grow X-ray quality single crystals were unsuccessful. Anal. \% Calcd for $[\mathrm{mC}] \mathrm{Cu}(\mathrm{OH})\left(\mathrm{ClO}_{4}\right) \cdot 0.55 \mathrm{H}_{2} \mathrm{O} \quad\left(\mathbf{4} \cdot 0.55 \mathrm{H}_{2} \mathrm{O}\right)$ $\mathrm{C}_{33} \mathrm{H}_{46} \mathrm{~N}_{5} \mathrm{O}_{8} \mathrm{CuCl} \cdot 0.55 \mathrm{H}_{2} \mathrm{O}: \mathrm{C}, 52.87 ; \mathrm{H}, 6.33 ; \mathrm{N}, 9.34$. Found: C, 52.63; H, 6.05; N, 9.49. MALDI: $m / z$ Calcd for $\left\{\mathrm{C}_{33} \mathrm{H}_{45} \mathrm{~N}_{5} \mathrm{O}_{4} \mathrm{Cu}\right\}^{+}:$638.3; found: $638.3\left(\{[\mathrm{mC}] \mathrm{Cu}(\mathrm{OH})-\mathrm{H}\}^{+}\right)$ (Figure S15). ESI-MS: $m / z$ Calcd for $\left\{\mathrm{C}_{33} \mathrm{H}_{46} \mathrm{~N}_{5} \mathrm{O}_{4} \mathrm{Cu}\right\}^{+}: 639.3$; found: 639.3 $\left(\{[\mathrm{mC}] \mathrm{Cu}(\mathrm{OH})\}^{+}\right)$(Figures S16-S17). X-band EPR spectrum (Acetonitrile, $77 \mathrm{~K}$ ) of $[\mathrm{mC}] \mathrm{Cu}(\mathrm{OH})\left(\mathrm{ClO}_{4}\right)$ (4) confirms the presence of $S=1 / 2 \mathrm{~d}^{9} \mathrm{Cu}^{\mathrm{II}}$ site (Figure S18). UV-Vis (Acetonitrile, $25^{\circ} \mathrm{C}$ ): very broad features. FTIR (KBr pellet): 3438 (m, br), 3257 (m), 2954 (s), 2870 (s), 1595 (s), 1487 (s), 1450 (s), 1361 (m), 1263 (s), 1159 (m), 1093 (s), 786 (w), 696 (m), 623 (s) (Figure S19). Powder X-ray diffraction pattern of 4 resulted in broad peaks (Figure S36). 
The independent synthesis of $\left[\mathrm{Cu}^{\mathrm{II}}\right]-\mathrm{OH}$ (4) from the reaction of $\mathbf{m C}$ with $\mathrm{Cu}\left(\mathrm{ClO}_{4}\right)_{2} \cdot 6 \mathrm{H}_{2} \mathrm{O}$ in presence of an equimolar amount of $\mathrm{NaOH}$ in acetonitrile was attempted. Unfortunately, several trials to isolate analytically pure $[\mathrm{mC}] \mathrm{Cu}^{\mathrm{II}}(\mathrm{OH})\left(\mathrm{ClO}_{4}\right)$ (4) were not successful. However, MALDI-TOF analysis of the resultant complex indicates the formation of $\left\{[\mathrm{mC}] \mathrm{Cu}^{\mathrm{II}}(\mathrm{OH})\right\}^{+}$species.

The solvent from the combined hexane wash was removed in vacuo to afford a solid. ${ }^{1} \mathrm{H}$ NMR and GC-MS analysis showed the presence of 3,3',5,5'-tetra-tert-butyl(1,1'-biphenyl)-2,2'-diol (5) (43\%) and unreacted 2,4-di-tert-butylphenol (2,4-DTBP) (unreacted 57\%) (Figure S22-S24).

${ }^{1} \mathrm{H}$ NMR of $5\left(500 \mathrm{MHz}, \mathrm{CDCl}_{3}\right) \delta 7.41(\mathrm{~d}, J=2.2 \mathrm{~Hz}, 1 \mathrm{H}, \mathrm{Ar}), 7.09(\mathrm{~d}, J=2.4$ $\mathrm{Hz}, 1 \mathrm{H}, \mathrm{Ar}), 5.25$ (s, 1H, OH), 1.46 (s, 9H, $\left.{ }^{t} \mathrm{Bu}\right), 1.33$ (s, 9H, $\left.{ }^{t} \mathrm{Bu}\right)$.

${ }^{1} \mathrm{H}$ NMR of unreacted 2,4-DTBP $\left(500 \mathrm{MHz}, \mathrm{CDCl}_{3}\right) \delta 7.31(\mathrm{~d}, J=2.3 \mathrm{~Hz}, 1 \mathrm{H}, \mathrm{Ar})$, 7.08 (dd, $J=8.2,2.4 \mathrm{~Hz}, 1 \mathrm{H}, \mathrm{Ar}), 6.60$ (d, $J=8.2 \mathrm{~Hz}, 1 \mathrm{H}, \mathrm{Ar}), 4.73$ (s, 1H, OH), 1.43 (s, $\left.1 \mathrm{H},{ }^{t} \mathrm{Bu}\right), 1.31\left(\mathrm{~s}, 1 \mathrm{H},{ }^{\mathrm{t}} \mathrm{Bu}\right)$.

The chemical shifts for compound $\mathbf{5}$ are comparable with the previous literatures. ${ }^{\mathrm{S} 6}$ GC-MS (EI) $m / z$ calcd for $\mathrm{C}_{28} \mathrm{H}_{42} \mathrm{O}_{2}[\mathrm{M}]^{+} 410$, found 410; ESI-MS(-): $m / z$ Calcd for $\mathrm{C}_{28} \mathrm{H}_{41} \mathrm{O}_{2}[\mathrm{M}-\mathrm{H}]^{-}$409.3, found 409.3.

A higher yield of 5 was observed in presence of excess 2,4-DTBP (Table S3), which can be attributed to the reaction of excess 2,4-DTBP with [CuII]-OH (4). Notably, copper(II)-OH complexes are known to react with substituted phenols to afford oxidatively coupled dimeric o, o'-biphenols. ${ }^{57}$

\subsection{Kinetic studies for the reaction of 1 a with 2,4-DTBP}

The kinetics of the reaction was monitored by UV-vis spectroscopic analysis at 65 ${ }^{\circ} \mathrm{C}$ by tracking the decay of the chromophore associated with complex $[\mathrm{mC}] \mathrm{Cu}\left(\kappa^{2}-\right.$ $\left.\mathrm{O}_{2} \mathrm{~N}\right)\left(\mathrm{ClO}_{4}\right)(\mathbf{1 a})$. A freshly prepared stock solution of $1 \mathbf{a}$ with $2.0 \mathrm{mM}$ concentration in anhydrous acetonitrile was used for the kinetic studies. A solution of $\mathbf{1 a}(2.0 \mathrm{~mL}, 2.0 \mathrm{mM}$, $4.0 \mu \mathrm{mol})$ in anhydrous acetonitrile was transferred to a quartz cuvette $(1 \mathrm{~cm}$ path length) containing calculated amount of 2,4-di-tert-butylphenol (2,4-DTBP) under anaerobic conditions. Then the cuvette was sealed with a rubber septum and placed in a cryostat (preset at $65^{\circ} \mathrm{C}$ ) connected to a UV-vis spectrometer. Subsequently, UV-vis absorption 
spectra with $300 \mathrm{~s}$ interval were collected for following the reaction. The exponential decay profile of the absorption feature centered at $670 \mathrm{~nm}$ was found to follow a pseudo-firstorder pattern for at least three half-lives (i.e. at least up to $\left.\ln \left\{\left(A_{\vdash}-A_{\mathrm{f}}\right) /\left(A_{\mathrm{i}}-A_{\mathrm{f}}\right)\right\}=-2.079\right)$. Straight line fittings of the $\ln \left\{\left(A_{\leftarrow}-A_{\mathrm{f}}\right) /\left(A_{\mathrm{i}}-A_{\mathrm{f}}\right)\right\}$ versus time plots corresponding to the decay curve provided the pseudo-first-order rate constant $\left(k_{\mathrm{obs}}\right) .{ }^{\mathrm{S} 8}$ The slope of the linear fitting of the $k_{\text {obs }}$ versus concentration of 2,4-DTBP provided the second order rate constants $\left(k_{2}\right)$ (Figure S26-S27 and Table S2).

Reactions of $[\mathrm{mC}] \mathrm{Cu}\left(\kappa^{2}-\mathrm{O}_{2} \mathrm{~N}\right)\left(\mathrm{ClO}_{4}\right)$ (1a) with 4-methoxyphenol, 4-tertbutylphenol, 4-methylphenol were performed by following the similar procedure as described for 2,4-DTBP (Figures S28-S29).

\section{Reaction of $[\mathrm{mC}] \mathrm{Zn}\left(\kappa^{2}-\mathrm{O}_{2} \mathrm{~N}\right)\left(\mathrm{ClO}_{4}\right)(1 \mathrm{~b})$ with 2,4-di-tert-butylphenol}

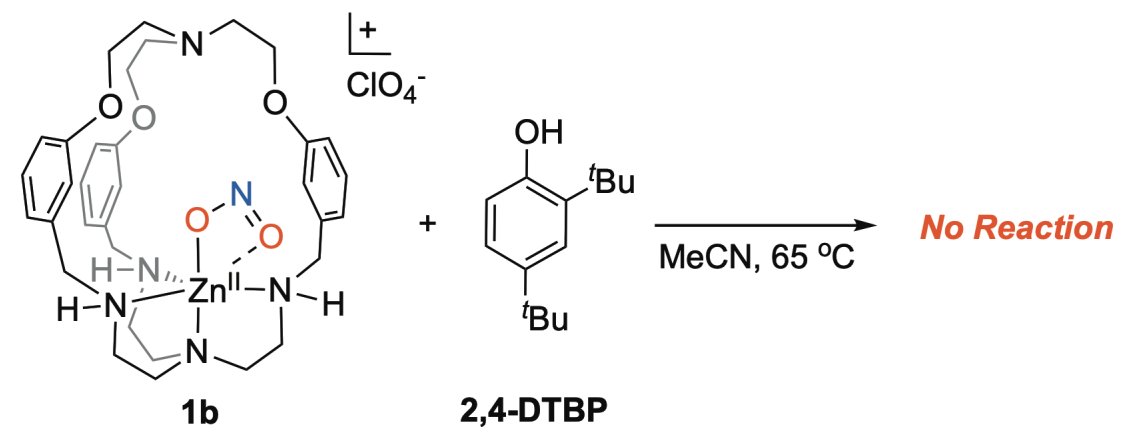

Scheme S6. Reaction of $\mathbf{1 b}$ with 2,4-DTBP.

A solution of $[\mathrm{mC}] \mathrm{Zn}\left(\kappa^{2}-\mathrm{O}_{2} \mathrm{~N}\right)\left(\mathrm{ClO}_{4}\right)(\mathbf{1 b})(0.100 \mathrm{~g}, 0.130 \mathrm{mmol})$ in anhydrous acetonitrile $(\sim 8 \mathrm{~mL})$ was transferred to a heavy-wall pressure vessel inside a glovebox. Ten equivalents of 2,4-di-tert-butylphenol (2,4-DTBP) $(0.267 \mathrm{~g}, 1.298 \mathrm{mmol})$ was added to the solution of $\mathbf{1 b}$ and the resultant reaction mixture heated at $65{ }^{\circ} \mathrm{C}$ for $72 \mathrm{~h}$. The resultant reaction mixture was dried in vacuo and hexane was added for extracting the phenolic components and precipitating the $\mathrm{Zn}$ product(s). The precipitate was separated by filtration and washed with hexane for several times. The solvent from the accumulated hexane wash was removed in vacuo to afford a solid. ${ }^{1} \mathrm{H}$ NMR and GC-MS analysis showed the presence of unreacted 2,4-di-tert-butylphenol (2,4-DTBP) only with trace amount of 3,3',5,5'-tetratert-butyl-(1,1'-biphenyl)-2,2'-diol (5) (Table S3). 
Characterization of the $\mathrm{Zn}$ product by comparing the powder X-ray diffraction patterns show the presence of unreacted $\mathbf{1 b}$ only (Figure S25).

\section{Reactions of $[\mathrm{mCH}] \mathrm{Cu}\left(\kappa^{2}-\mathrm{O}_{2} \mathrm{~N}\right)\left(\mathrm{ClO}_{4}\right)_{2}$ (3) with 2,4-di-tert-butylphenol}

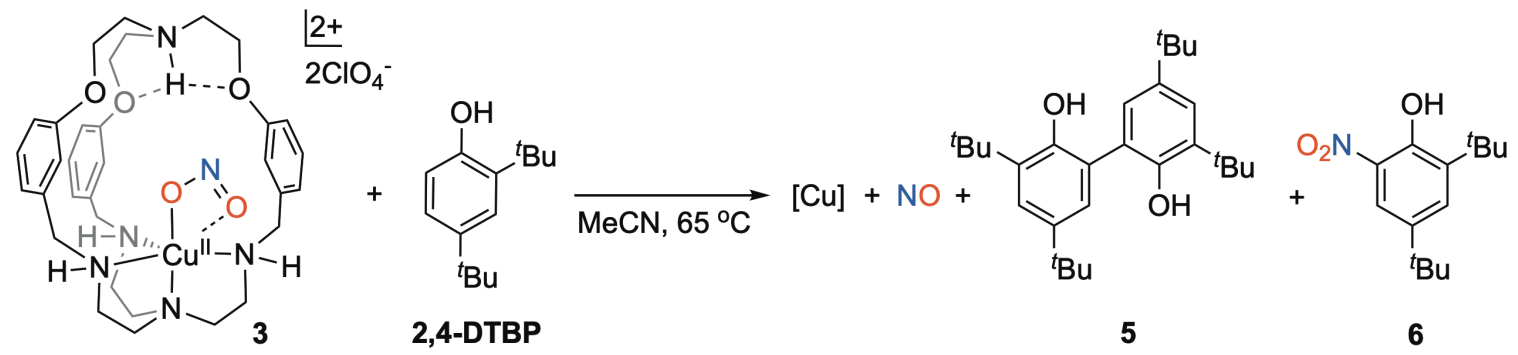

Scheme S7. Reaction of 3 with 2,4-DTBP.

\subsection{Product analysis for the reaction of 3 with 2,4-DTBP}

A solution of $[\mathrm{mCH}] \mathrm{Cu}\left(\kappa^{2}-\mathrm{O}_{2} \mathrm{~N}\right)\left(\mathrm{ClO}_{4}\right)_{2}(3)(0.100 \mathrm{~g}, 0.115 \mathrm{mmol})$ in anhydrous acetonitrile $(\sim 8 \mathrm{~mL})$ was transferred to a heavy-wall pressure vessel inside a glovebox. One equivalent of 2,4-di-tert-butylphenol (2,4-DTBP) $(0.024 \mathrm{~g}, 0.115 \mathrm{mmol})$ was added to the solution of 3 and the resultant reaction mixture warmed at $65^{\circ} \mathrm{C}$ until the initial greenish color turns to faint greenish-yellow. The resultant reaction mixture was dried in vacuo and hexane was added for extracting the organic products and precipitating the greenish-yellow $\mathrm{Cu}$ product(s). The faint greenish-yellow residue was separated by filtration and washed with hexane for several times and dried in vacuo. Elemental analyses of the complex were not assignable. Several attempts to grow X-ray quality single crystals were unsuccessful, thereby leaving the identity of the copper product(s) unknown. X-band EPR spectrum (Acetonitrile, $77 \mathrm{~K}$ ) of crude reaction mixture confirms the presence of $S=1 / 2 \mathrm{~d}^{9} \mathrm{Cu}^{\mathrm{II}}$ site (Figure S34). UV-Vis (Acetonitrile, $25^{\circ} \mathrm{C}$ ): very broad features (Figure S37). Powder Xray diffraction pattern of the precipitate shows broad peaks (Figure S36). FTIR (KBr pellet): 3523 (m, br), 3250 (m), 2956 (s), 1589 (s), 1487 (m), 1452 (s), 1367 (m), 1361 (m), 1265 (s), 1091 (s), 786 (m), 696 (m), 624 (s) (Figure S35).

The solvent from the combined hexane wash was evaporated in vacuo to afford a solid. ${ }^{1} \mathrm{H}$ NMR and GC-MS analysis showed the presence of 3,3',5,5'-tetra-tert-butyl(1,1'-biphenyl)-2,2'-diol (5) (31\%), 6-nitro-2,4-di-tert-butylphenol (6) (8\%), and unreacted 2,4-di-tert-butylphenol (2,4-DTBP) (unreacted 61\%) (Figures S22-S24). 
${ }^{1} \mathrm{H} \mathrm{NMR}$ of $5\left(500 \mathrm{MHz}, \mathrm{CDCl}_{3}\right) \delta 7.41(\mathrm{~d}, J=2.2 \mathrm{~Hz}, 1 \mathrm{H}, \mathrm{Ar}), 7.09$ (d, $J=2.4$ $\mathrm{Hz}, 1 \mathrm{H}, \mathrm{Ar}), 5.25$ (s, 1H, OH), 1.46 (s, 9H, $\left.{ }^{t} \mathrm{Bu}\right), 1.33$ (s, 9H, ${ }^{t} \mathrm{Bu}$ ). ESI-MS(-): $m / z$ Calcd for $\mathrm{C}_{28} \mathrm{H}_{41} \mathrm{O}_{2}[\mathrm{M}-\mathrm{H}]^{-} 409.3$, found 409.3. GC-MS (EI) $m / z$ calcd for $\mathrm{C}_{28} \mathrm{H}_{42} \mathrm{O}_{2}[\mathrm{M}]^{+} 410$, found 410 .

${ }^{1} \mathrm{H}$ NMR of $6\left(500 \mathrm{MHz}, \mathrm{CDCl}_{3}\right) \delta 11.46(\mathrm{~s}, 1 \mathrm{H}, \mathrm{OH}), 7.97$ (d, $\left.J=2.4 \mathrm{~Hz}, 1 \mathrm{H}, \mathrm{Ar}\right)$, $7.65(\mathrm{~d}, J=2.4 \mathrm{~Hz}, 1 \mathrm{H}, \mathrm{Ar}), 1.46\left(\mathrm{~s}, 9 \mathrm{H},{ }^{t} \mathrm{Bu}\right), 1.33\left(\mathrm{~s}, 9 \mathrm{H},{ }^{t} \mathrm{Bu}\right)$. The chemical shifts for the aliphatic C-H of compound 5 and 6 overlap. ESI-MS(-): $m / z$ Calcd for $\mathrm{C}_{14} \mathrm{H}_{20} \mathrm{NO}_{3}[\mathrm{M}-$ $\mathrm{H}]^{-}$250.1, found 250.1. GC-MS (EI) $m / z$ calcd for $\mathrm{C}_{14} \mathrm{H}_{21} \mathrm{NO}_{3}[\mathrm{M}]^{+} 251$, found 251 .

${ }^{1} \mathrm{H}$ NMR of unreacted 2,4-DTBP $\left(500 \mathrm{MHz}, \mathrm{CDCl}_{3}\right) \delta 7.31$ (d, $\left.J=2.3 \mathrm{~Hz}, 1 \mathrm{H}, \mathrm{Ar}\right)$, 7.08 (dd, $J=8.2,2.4 \mathrm{~Hz}, 1 \mathrm{H}, \mathrm{Ar}), 6.60$ (d, $J=8.2 \mathrm{~Hz}, 1 \mathrm{H}, \mathrm{Ar}), 4.73$ (s, 1H, OH), 1.43 (s, $\left.1 \mathrm{H},{ }^{t} \mathrm{Bu}\right), 1.31\left(\mathrm{~s}, 1 \mathrm{H},{ }^{t} \mathrm{Bu}\right)$.

The chemical shifts for compound $\mathbf{5}$ and $\mathbf{6}$ are comparable with the previous literatures (Figure S22). ${ }^{\mathrm{S} 6}$ Higher yield of $\mathbf{5}$ was observed in presence of excess $\mathrm{NaNO}_{2}$ (Figure S22-S24 and Table S3).

\subsection{Kinetic studies for the reaction of 3 with 2,4-DTBP}

The kinetics of the reaction was monitored by UV-vis spectroscopic analysis at 65 ${ }^{\circ} \mathrm{C}$ by tracking the decay of the chromophore associated with complex $[\mathrm{mCH}] \mathrm{Cu}\left(\kappa^{2}-\right.$ $\left.\mathrm{O}_{2} \mathrm{~N}\right)\left(\mathrm{ClO}_{4}\right)_{2}(3)$. A stock solution of $\mathbf{3}$ with $2.0 \mathrm{mM}$ concentration in anhydrous acetonitrile was used for the kinetic studies. A solution of $\mathbf{3}(2.0 \mathrm{~mL}, 2.0 \mathrm{mM}, 4.0 \mu \mathrm{mol})$ in anhydrous acetonitrile was transferred to a quartz cuvette $(1 \mathrm{~cm}$ path length) containing calculated amount of 2,4-di-tert-butylphenol (2,4-DTBP) under anaerobic conditions. Then the cuvette was sealed with a rubber septum and placed in a cryostat (at $65^{\circ} \mathrm{C}$ ) connected to a $\mathrm{UV}$-vis spectrometer. Subsequently, UV-vis absorption spectra with $300 \mathrm{~s}$ interval were collected for following the reaction. The decay profile of the absorption feature centered at $660 \mathrm{~nm}$ was followed. In contrast to the well-behaved decay profile of complex 1a in presence of excess 2,4-DTBP at $65{ }^{\circ} \mathrm{C}$, decay of complex 3 under similar reaction conditions does not follow any regular kinetic pattern. While the decay profile of $\mathbf{3}$ during the reaction with excess 2,4-DTBP at $65{ }^{\circ} \mathrm{C}$ was not well-behaved (Figures S31-S32), multiple kinetic experiments confirmed the consistency of the decay profile. 


\subsection{Reactions of 3 with 2,4-DTBP in presence of free $\mathrm{NO}_{2}^{-}$}

A solution of $[\mathrm{mCH}] \mathrm{Cu}\left(\kappa^{2}-\mathrm{O}_{2} \mathrm{~N}\right)\left(\mathrm{ClO}_{4}\right)_{2}(3)(0.100 \mathrm{~g}, 0.115 \mathrm{mmol})$ in anhydrous acetonitrile $(\sim 8 \mathrm{~mL})$ was transferred to a heavy-wall pressure vessel inside a glovebox. One equivalent of 2,4-di-tert-butylphenol (2,4-DTBP) $(0.024 \mathrm{~g}, 0.115 \mathrm{mmol})$ and ten equivalents $\mathrm{NaNO}_{2}(0.080 \mathrm{~g}, 1.150 \mathrm{mmol})$ were added to the solution of $\mathbf{3}$ and the resultant reaction mixture warmed at $65^{\circ} \mathrm{C}$ until the initial greenish color disappeared completely. The resultant reaction mixture was filtered and the filtrate was dried in vacuo. Hexane was

added to the crude material for extracting the organic products. The solvent from the combined hexane wash was evaporated in vacuo to afford a solid. ${ }^{1} \mathrm{H}$ NMR and GC-MS analysis showed the presence of 3,3',5,5'-tetra-tert-butyl-(1,1'-biphenyl)-2,2'-diol (5) (18\%), 6-nitro-2,4-di-tert-butylphenol (6) (20\%), and unreacted 2,4-di-tert-butylphenol (2,4-DTBP) (unreacted 62\%) (Figures S22-S24).

Reactions of 1a/ 1b with 2,4-DTBP under analogous reaction conditions in presence of free $\mathrm{NO}_{2}{ }^{-}$anion did not afford 6-nitro-2,4-di-tert-butylphenol (6) (Table S3). 


\section{Qualitative NO trapping by $(\mathrm{dtc})_{2} \mathrm{Fe}^{\mathrm{II}}$ Complex.}

As described in the literature, ${ }^{\mathrm{S} 9} \mathrm{Bis}(\mathrm{N}, \mathrm{N}$-diethyldithiocarbamato)iron(II) $\left[(\mathrm{dtc})_{2} \mathrm{Fe}^{\mathrm{II}}\right]$ complex was used for trapping nitric oxide. $(\mathrm{dtc})_{2} \mathrm{Fe}^{\mathrm{II}}$ was synthesized according to a previously reported procedure. ${ }^{\mathrm{S} 10}$

A round-bottom flask containing a solution of $1 \mathrm{a}(0.100 \mathrm{~g}, 0.130 \mathrm{mmol})$ in $\mathrm{CH}_{3} \mathrm{CN}$ was connected to another round-bottom flask containing a solution of (dtc) ${ }_{2} \mathrm{Fe}^{\mathrm{II}}$ complex (0.023 g, $0.065 \mathrm{mmol})$ in $\mathrm{CH}_{2} \mathrm{Cl}_{2}$ via a cannula. Excess 2,4-di-tert-butylphenol (2,4-DTBP) ( $0.268 \mathrm{~g}, 1.301 \mathrm{mmol}, 10$ equivalents) was added to the solution of $\mathbf{1 a}$ and the resultant reaction mixture warmed at $65^{\circ} \mathrm{C}$ until the initial greenish color turns to yellowish. The evolved nitric oxide was bubbled through the solution consisting (dtc $)_{2} \mathrm{Fe}^{\mathrm{II}}$. The resultant solution of Fe complex was analyzed by X-band EPR and IR spectroscopic analyses.

The X-band EPR spectrum (Dichloromethane, $77 \mathrm{~K}$ ) (Figure S21) of the resultant $(\mathrm{dtc})_{2} \mathrm{Fe}^{\mathrm{II}}$ complex exhibits typical $S=1 / 2$ signal centered near $g \approx 2.04$ with ${ }^{14} \mathrm{~N}$-hyperfine splitting, which is characteristic of $(\mathrm{dtc})_{2} \mathrm{Fe}(\mathrm{NO})$ complex. ${ }^{\mathrm{S} 11}$ The IR spectrum of $(\mathrm{dtc})_{2} \mathrm{Fe}(\mathrm{NO})$ complex exhibits a vibrational band at $1707 \mathrm{~cm}^{-1}$ (Figure S20), which can be corroborated to $v_{\mathrm{NO}}$ of (dtc) $)_{2} \mathrm{Fe}(\mathrm{NO})$ complex $^{\mathrm{S} 11}$. FTIR (KBr pellet): 2974 (m), 1707 (m, NO), 1490 (s), 1454 (s), 1431 (s), 1352 (m), 1269 (s), 1207 (m), 1141 (m), 1072 (m), 993 (m), $914(\mathrm{~m}), 842(\mathrm{~m}), 738(\mathrm{~m}), 567(\mathrm{~m})$.

Qualitative NO trapping for the released NO from the reaction of 3 with excess 2,4di-tert-butylphenol (2,4-DTBP) were carried out employing a similar procedure as described above.

As the reactions of 2,4-DTBP with $1 \mathrm{a}$ and 3 are very slow, quantitation of the released NO was hindered. 


\section{Figures and Tables}

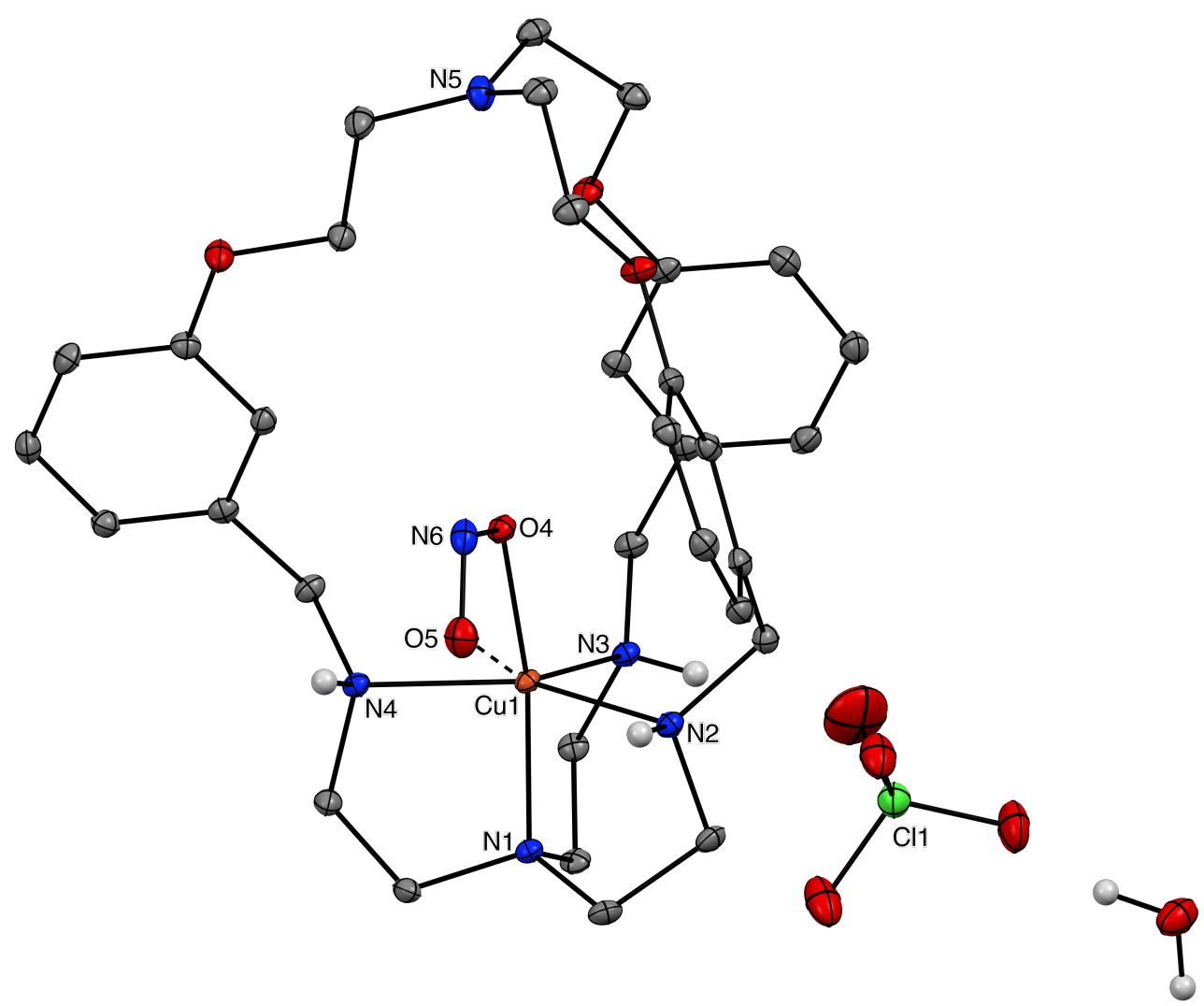

Figure S1. X-ray crystal structure of $[\mathrm{mC}] \mathrm{Cu}\left(\kappa^{2}-\mathrm{O}_{2} \mathrm{~N}\right)\left(\mathrm{ClO}_{4}\right)(\mathbf{1 a})(\mathrm{CCDC} 1960186)$. $\mathbf{1 a}$ is found to cocrystallize with one $\mathrm{H}_{2} \mathrm{O}$ molecule. The thermal ellipsoid plots are drawn at $30 \%$ probability level. Hydrogen atoms on carbons are omitted for clarity. Selected bond distances $(\AA)$ and angles $\left(^{\circ}\right)$ : Cu1-N1 2.0302(14), Cu1-N2 2.0767(15), Cu1-N3 2.2358(15),

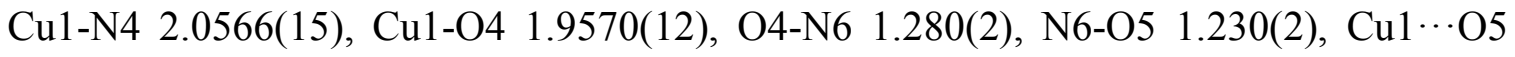
2.626, N1-Cu1-N2 85.35(6), N1-Cu1-N3 83.88(6), N1-Cu1-N4 84.79(6), N2-Cu1-N3 96.80(6), N4-Cu1-N3 104.00(6), N4-Cu1-N2 155.84(6), O4-Cu1-N1 167.62(6), O4-Cu1N2 95.38(5), O4-Cu1-N3 108.25(5), O4-Cu1-N4 89.71(5), N6-O4-Cu1 112.52(11), O5N6-O4 114.01(14). 


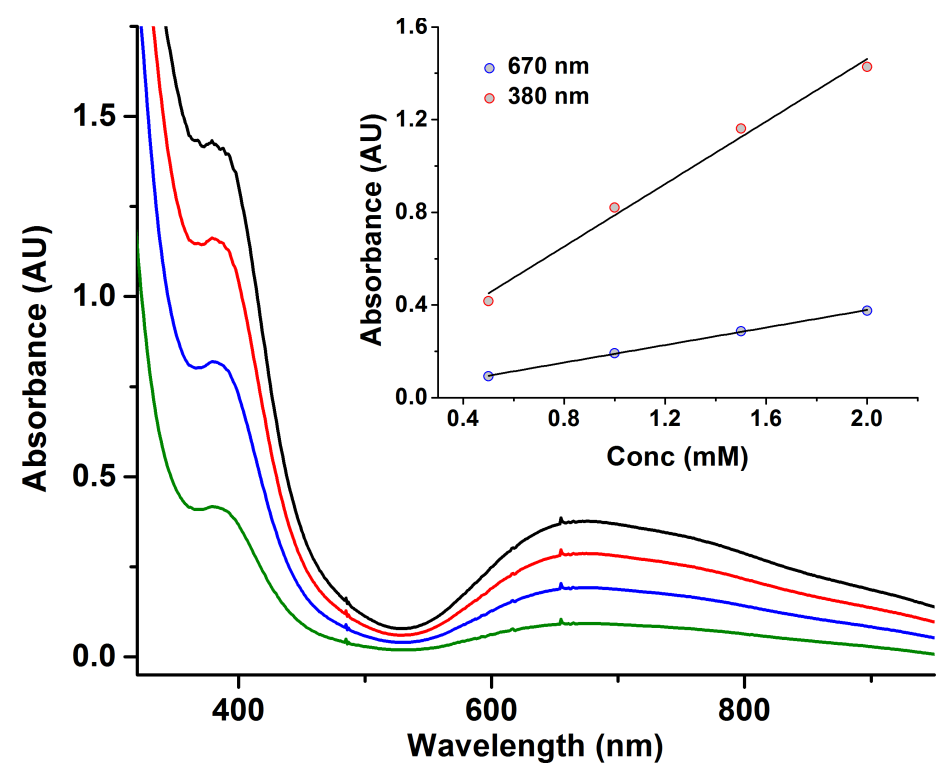

Figure S2. UV-vis spectra of $[\mathrm{mC}] \mathrm{Cu}\left(\kappa^{2}-\mathrm{O}_{2} \mathrm{~N}\right)\left(\mathrm{ClO}_{4}\right)(\mathbf{1 a})$ in acetonitrile at $25{ }^{\circ} \mathrm{C}$ for different concentrations $(0.5,1.0,1.5$, and $2.0 \mathrm{mM})$. Inset: Beer's law (Absorbance versus concentration) plot for $[\mathrm{mC}] \mathrm{Cu}\left(\kappa^{2}-\mathrm{O}_{2} \mathrm{~N}\right)\left(\mathrm{ClO}_{4}\right)$ (1a) depicts $\lambda_{\max } / \mathrm{nm}\left(\varepsilon / \mathrm{M}^{-1} \mathrm{~cm}^{-1}\right)=380$ (675) and 670 (190).

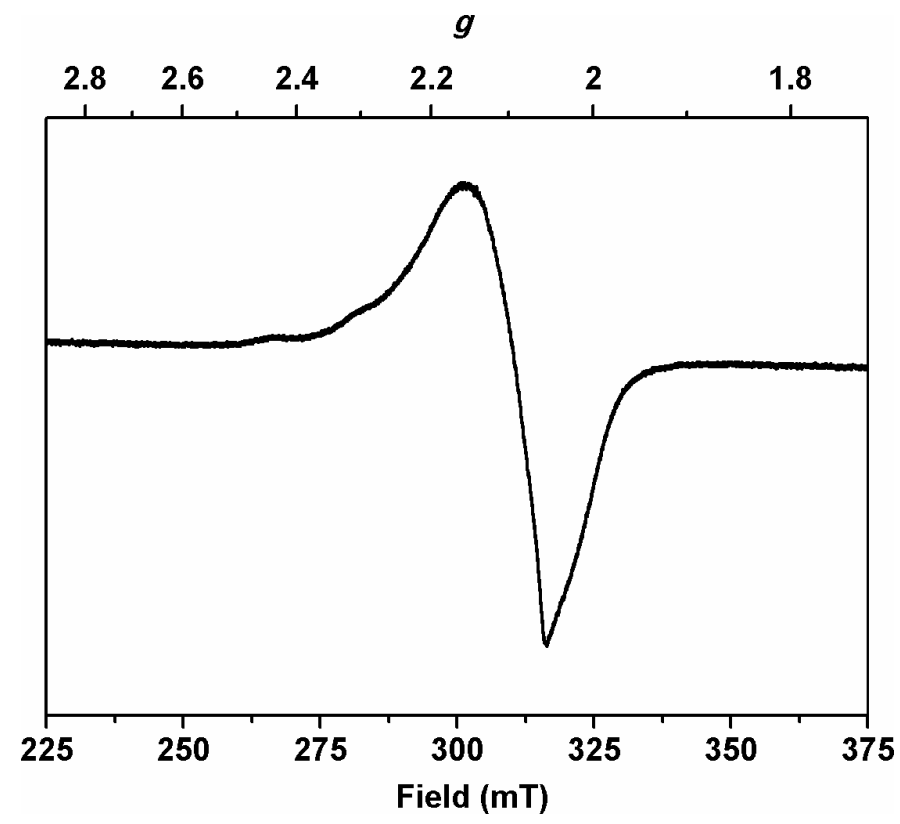

Figure S3. X-band EPR spectrum (Acetonitrile, $77 \mathrm{~K})$ of $[\mathrm{mC}] \mathrm{Cu}\left(\kappa^{2}-\mathrm{O}_{2} \mathrm{~N}\right)\left(\mathrm{ClO}_{4}\right)(\mathbf{1 a})$. Data collection parameters: Frequency $=9092.167 \mathrm{MHz}$, Power $=0.995 \mathrm{~mW}$, ModWidth $=0.1 \mathrm{mT}$, time constant $=0.1 \mathrm{~s}$. 


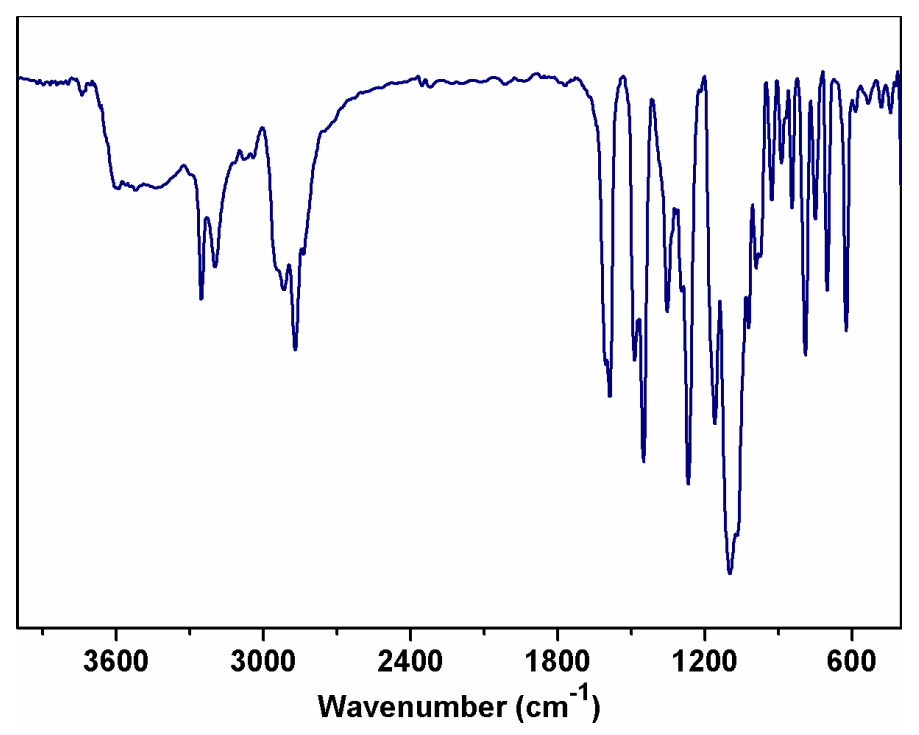

Figure S4. FTIR (KBr pellet) spectrum of $[\mathrm{mC}] \mathrm{Cu}\left(\kappa^{2}-\mathrm{O}_{2} \mathrm{~N}\right)\left(\mathrm{ClO}_{4}\right)(\mathbf{1 a})$. 


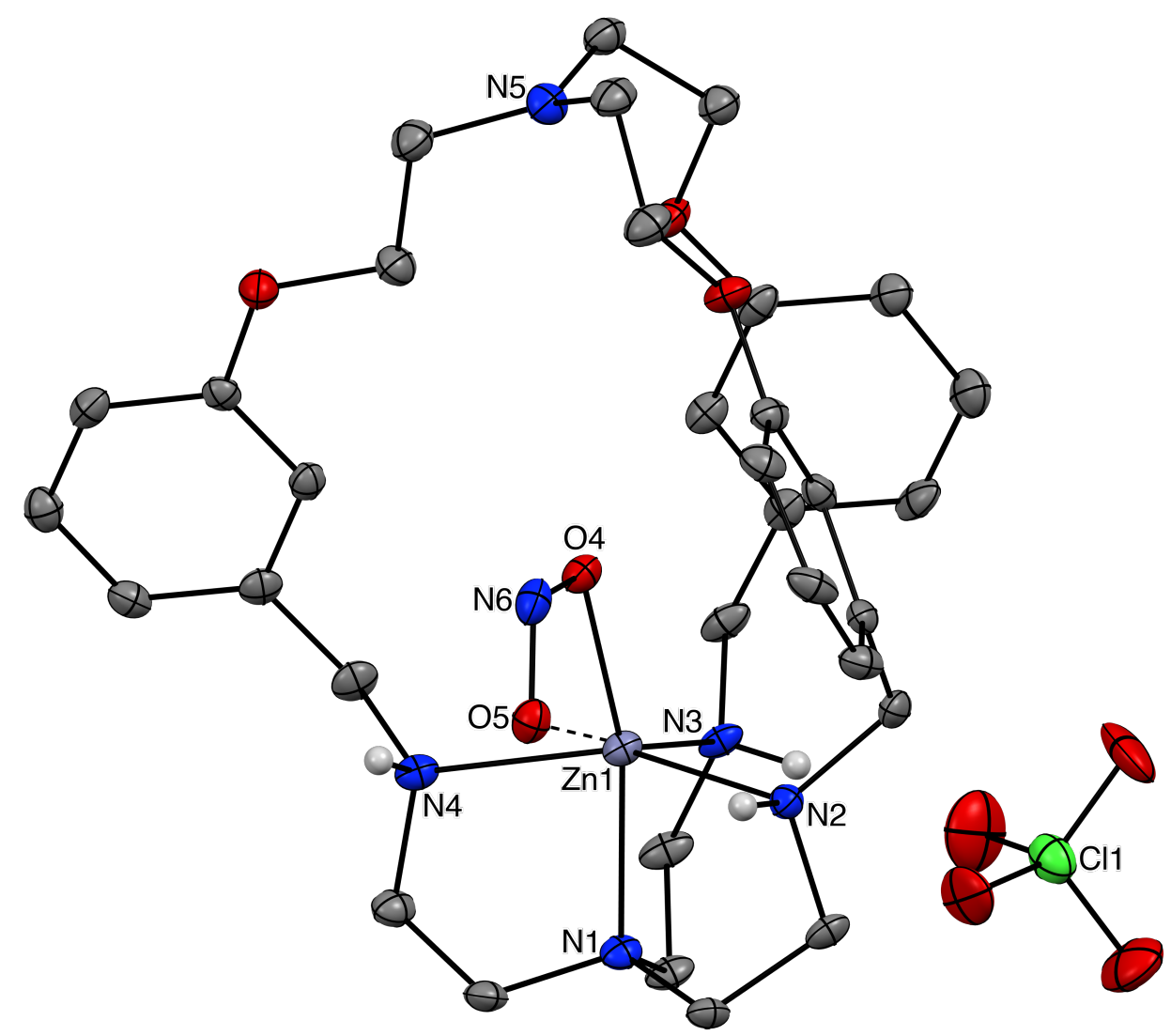

Figure S5. X-ray crystal structure of $[\mathrm{mC}] \mathrm{Zn}\left(\kappa^{2}-\mathrm{O}_{2} \mathrm{~N}\right)\left(\mathrm{ClO}_{4}\right)(\mathbf{1 b})(\mathrm{CCDC} 1960187)$. The thermal ellipsoid plots are drawn at 30\% probability level. Hydrogen atoms on carbons are omitted for clarity. Selected bond distances $(\AA)$ and angles $\left(^{\circ}\right)$ : Zn1-N1 2.135(3), Zn1-N2 2.212(3), Zn1-N3 2.080(3), Zn1-N4 2.213(3), Zn1-O4 2.041(2), O4-N6 1.277(4), N6-O5

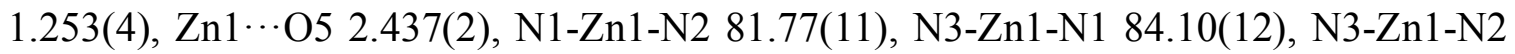
98.73(12), N3-Zn1-N4 104.20(12), N1-Zn1-N4 80.84(11), N2-Zn1-N4 149.47(11), O4Zn1-N3 115.79(11), O4-Zn1-N1 159.87(11), O4-Zn1-N2 97.30(10), O4-Zn1-N4 90.66(10), O4-Zn1-O5 55.41(9), N6-O4-Zn1 104.9(2), N6-O5-Zn1 86.51(19), O5-N6-O4 113.1(3). 


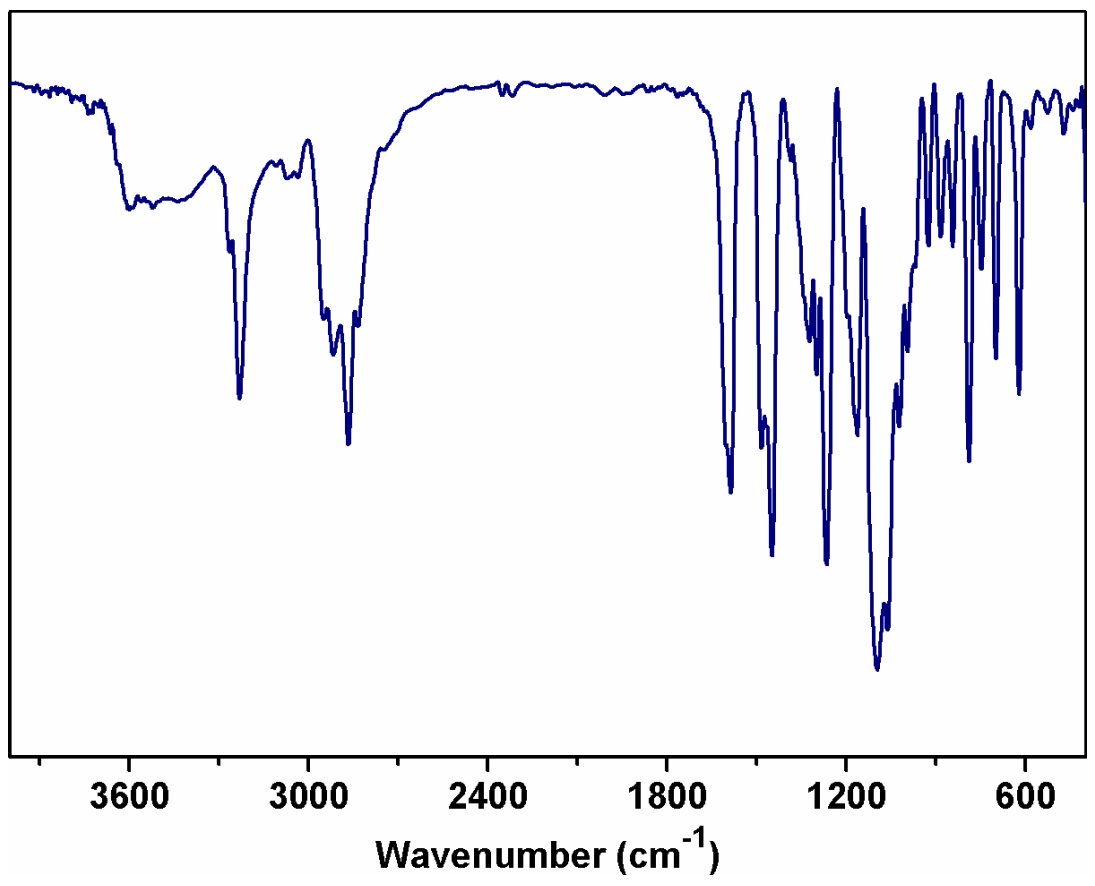

Figure S6. FTIR (KBr pellet) spectrum of $[\mathrm{mC}] \mathrm{Zn}\left(\kappa^{2}-\mathrm{O}_{2} \mathrm{~N}\right)\left(\mathrm{ClO}_{4}\right)(\mathbf{1 b})$. 

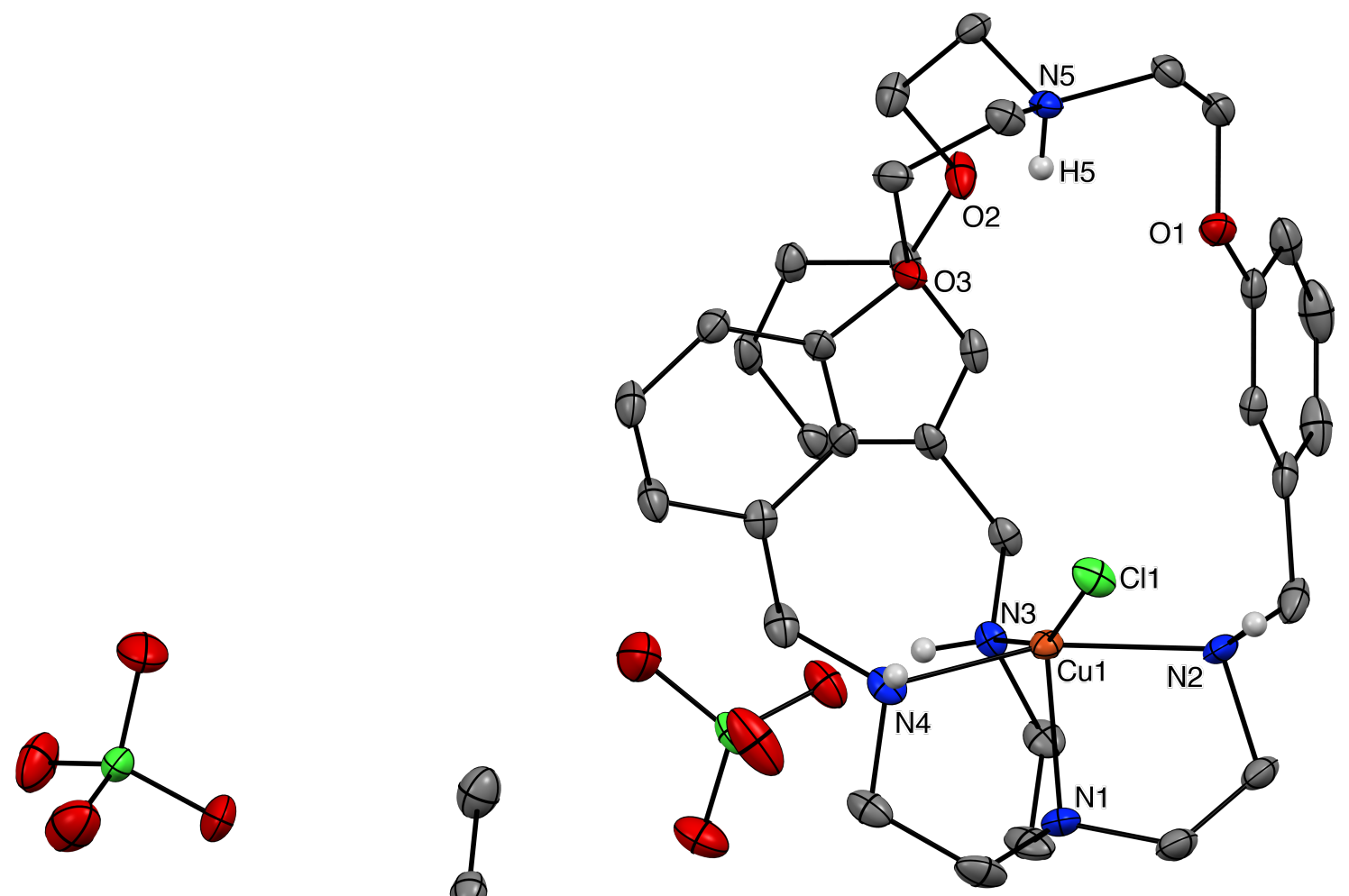

Figure S7. X-ray crystal structure of $[\mathrm{mCH}] \mathrm{CuCl}\left(\mathrm{ClO}_{4}\right)_{2}$ (2) (CCDC 1960188). 2 is found to cocrystallize with one $\mathrm{MeCN}$ molecule. The thermal ellipsoid plots are drawn at 30\% probability level. Hydrogen atoms on carbons are omitted for clarity. Selected bond distances $(\AA)$ and angles ( $\left.{ }^{\circ}\right)$ : Cu1-N1 2.151(2), Cu1-N2 2.104(12), Cu1-N3 2.107(2), Cu1-

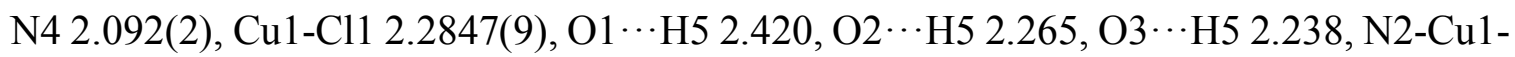
N1 82.3(2), N3-Cu1-N1 83.43(10), N4-Cu1-N1 84.60(9), N4-Cu1-Cl1 89.18(6), N3-Cu1Cl1 157.71(6), N2-Cu1-Cl1 85.3(4), N1-Cu1-Cl1 118.86(8). 


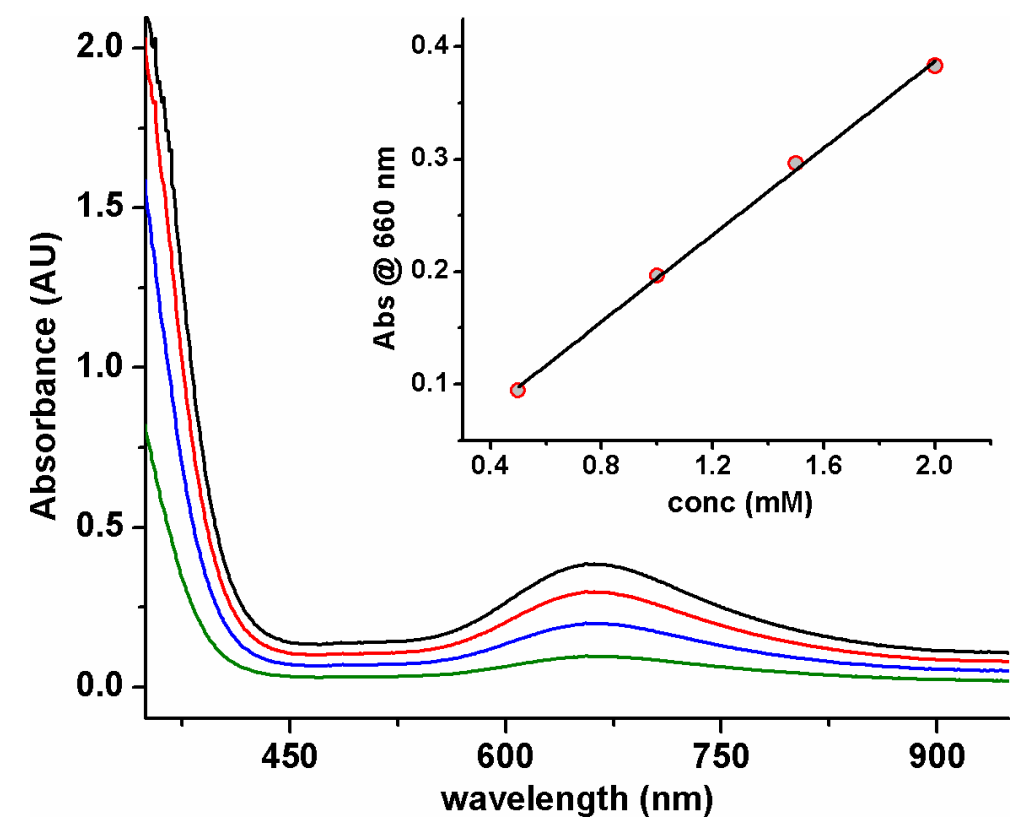

Figure S8. UV-vis spectra of $[\mathrm{mCH}] \mathrm{CuCl}\left(\mathrm{ClO}_{4}\right)_{2}(2)$ in acetonitrile at $25^{\circ} \mathrm{C}$ for different concentrations $(0.5,1.0,1.5$, and $2.0 \mathrm{mM}$ ). Inset: Beer's law (Absorbance versus concentration) plot for $[\mathrm{mCH}] \mathrm{Cu}(\mathrm{Cl})\left(\mathrm{ClO}_{4}\right)_{2}(2)$ depicts $\lambda_{\max } / \mathrm{nm}\left(\varepsilon / \mathrm{M}^{-1} \mathrm{~cm}^{-1}\right)=660(190)$.

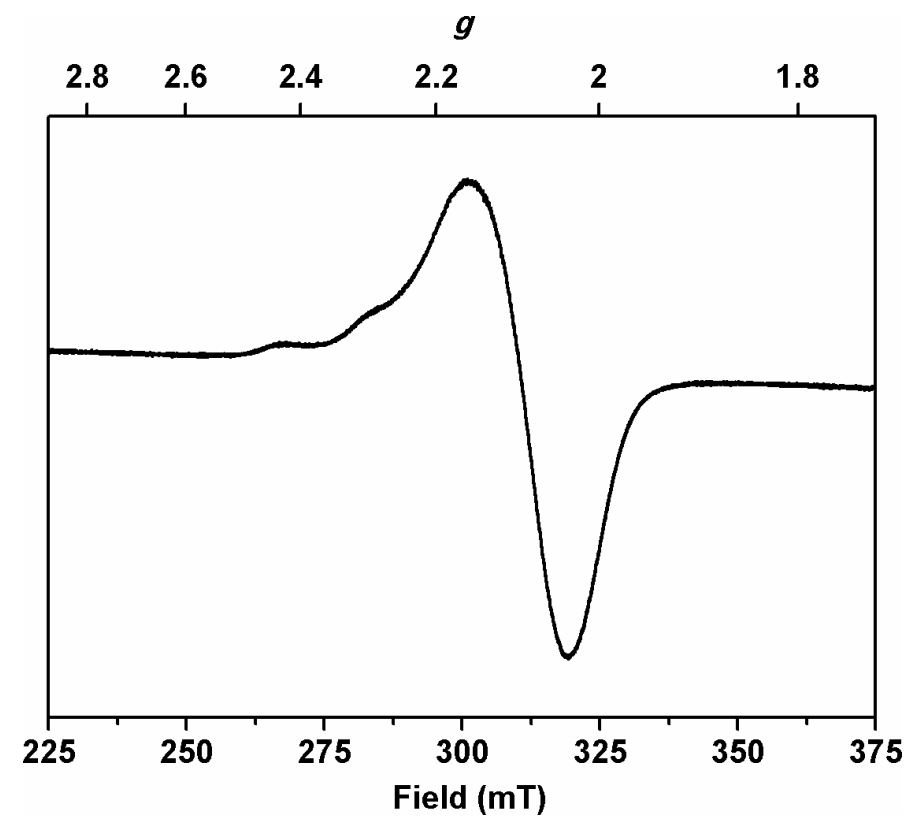

Figure S9. X-band EPR spectrum (Acetonitrile, $77 \mathrm{~K}$ ) of $[\mathrm{mCH}] \mathrm{CuCl}\left(\mathrm{ClO}_{4}\right)_{2}$ (2). Data collection parameters: Frequency $=9092.167 \mathrm{MHz}$, Power $=0.995 \mathrm{~mW}$, ModWidth $=0.1$ $\mathrm{mT}$, time constant $=0.1 \mathrm{~s}$. 


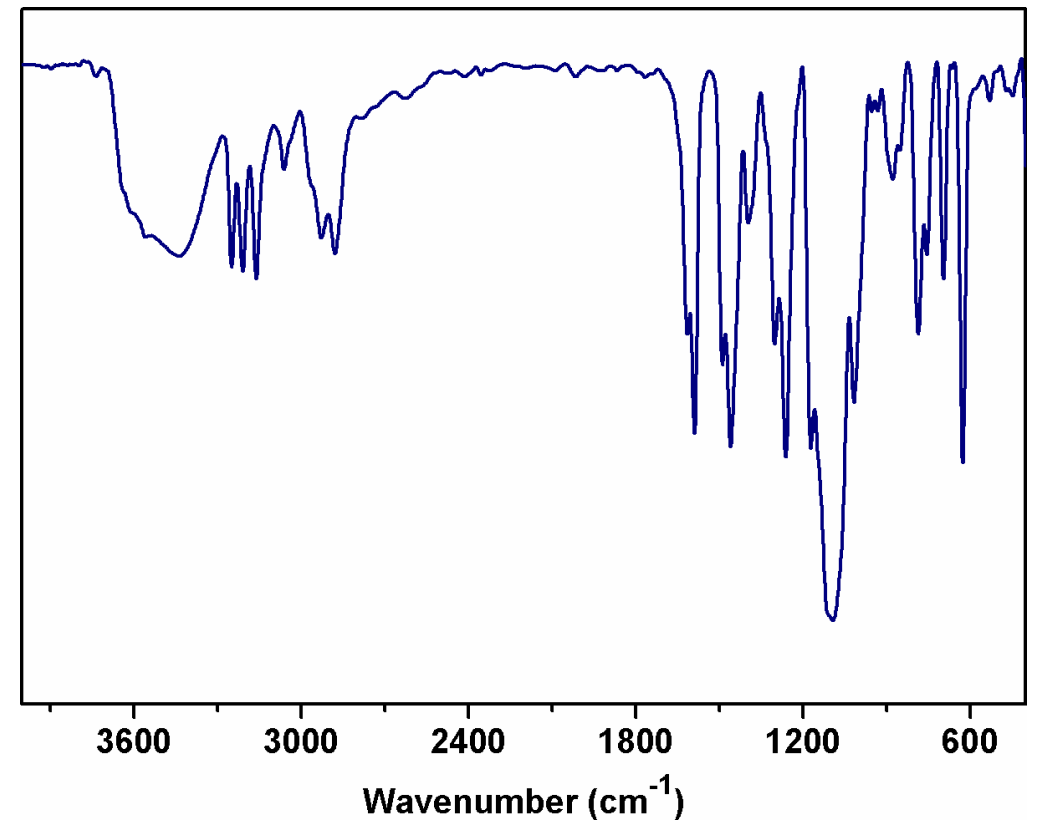

Figure S10. FTIR ( $\mathrm{KBr}$ pellet) spectrum of $[\mathrm{mCH}] \mathrm{CuCl}\left(\mathrm{ClO}_{4}\right)_{2}(\mathbf{2})$. 


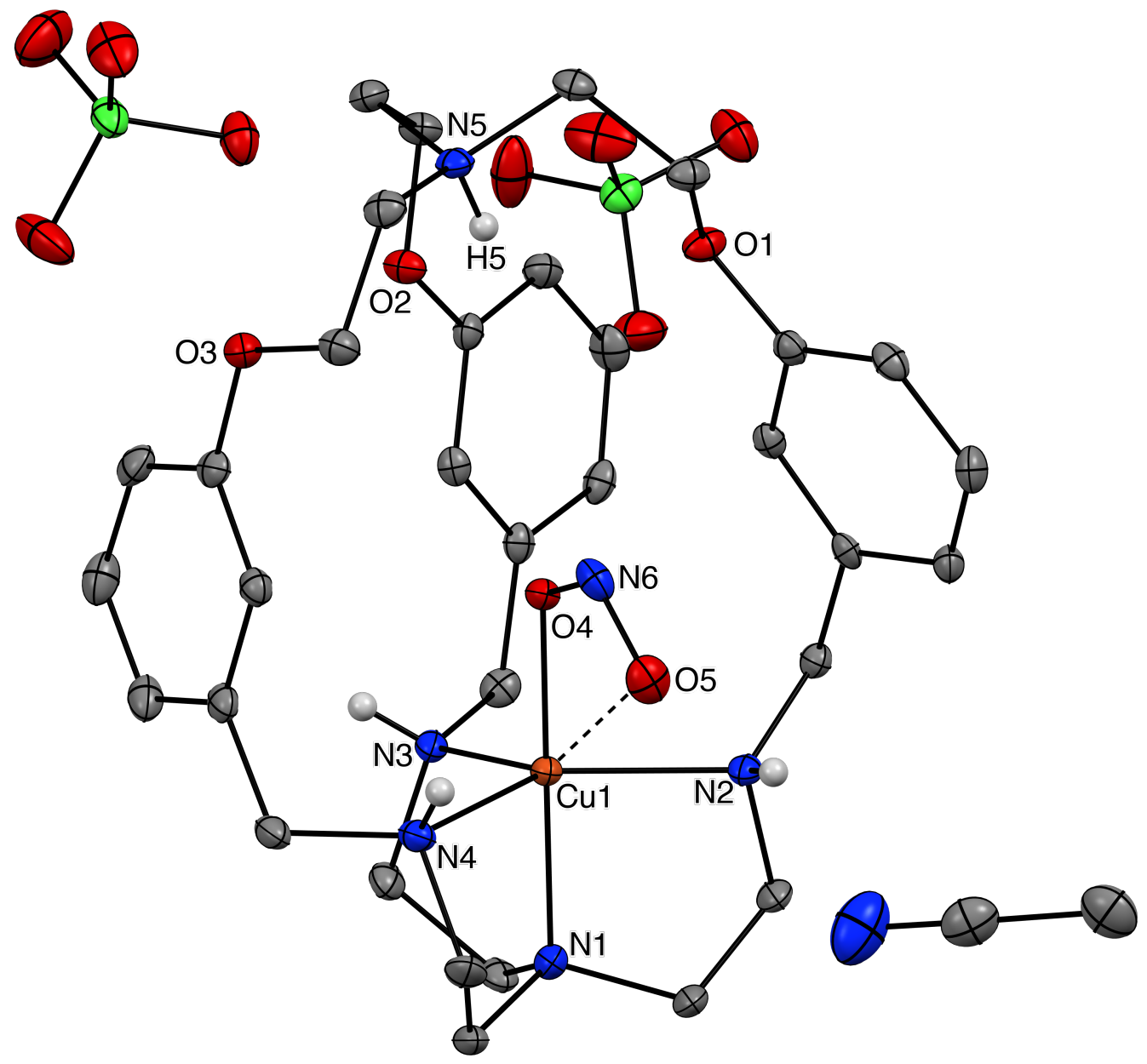

Figure S11. X-ray crystal structure of $[\mathrm{mCH}] \mathrm{Cu}\left(\kappa^{2}-\mathrm{O}_{2} \mathrm{~N}\right)\left(\mathrm{ClO}_{4}\right)_{2}$ (3) (CCDC 1960189). 3 is found to cocrystallize with one $\mathrm{MeCN}$ molecule. The thermal ellipsoid plots are drawn at $30 \%$ probability level. Hydrogen atoms on carbons are omitted for clarity. Selected bond distances $(\AA)$ and angles $\left({ }^{\circ}\right)$ : Cu1-N1 2.046(4), Cu1-N2 2.092(4), Cu1-N3 2.227(3), Cu1-

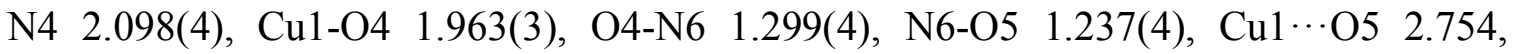

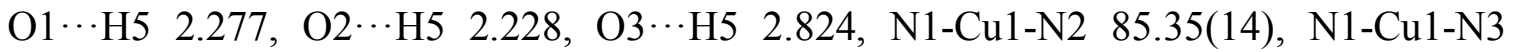
83.06(13), N1-Cu1-N4 85.09(14), N2-Cu1-N3 109.32(15), N4-Cu1-N3 107.29(14), N2Cu1-N4 140.62(14), O4-Cu1-N1 174.18(13), O4-Cu1-N2 95.63(13), O4-Cu1-N3 101.96(12), O4-Cu1-N4 90.56(13), N6-O4-Cu1 116.3(2), O5-N6-O4 114.4(4). 


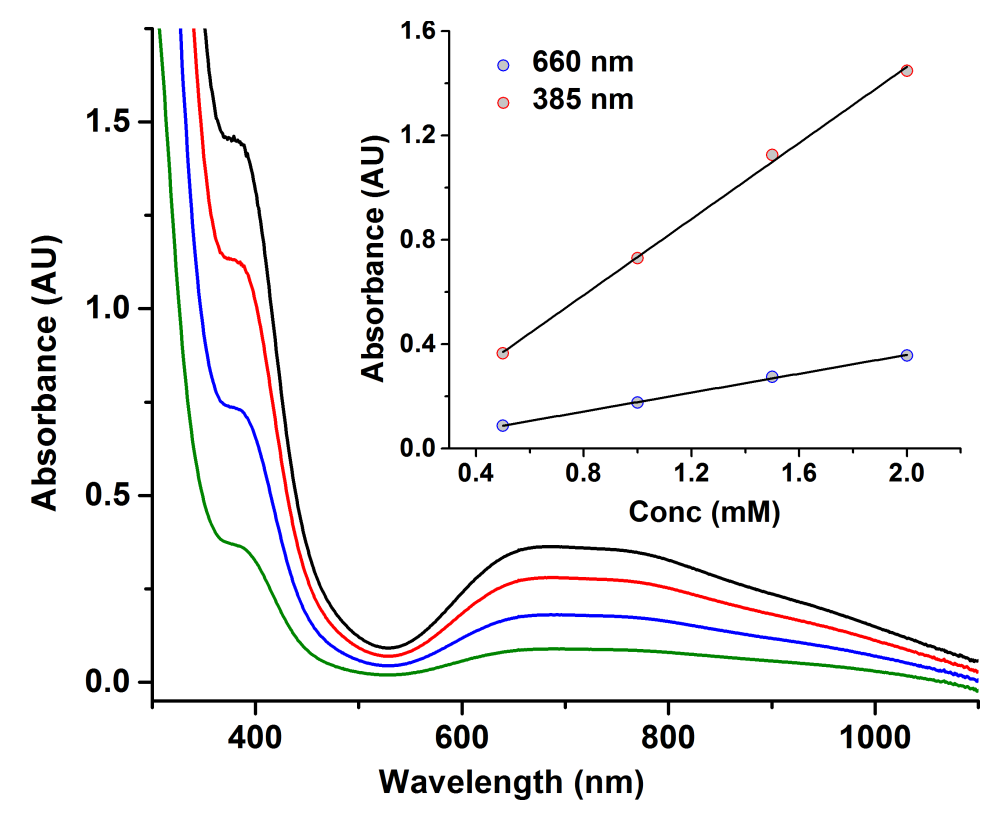

Figure S12. UV-vis spectra of $[\mathrm{mCH}] \mathrm{Cu}\left(\kappa^{2}-\mathrm{O}_{2} \mathrm{~N}\right)\left(\mathrm{ClO}_{4}\right)_{2}(3)$ in acetonitrile at $25{ }^{\circ} \mathrm{C}$ for different concentrations $(0.5,1.0,1.5$, and $2.0 \mathrm{mM})$. Inset: Beer's law (Absorbance versus concentration) plot for $[\mathrm{mCH}] \mathrm{Cu}\left(\kappa^{2}-\mathrm{O}_{2} \mathrm{~N}\right)\left(\mathrm{ClO}_{4}\right)_{2}$ (3) depicts $\lambda_{\max } / \mathrm{nm}\left(\varepsilon / \mathrm{M}^{-1} \mathrm{~cm}^{-1}\right)=385$ 730) and 660 (180).

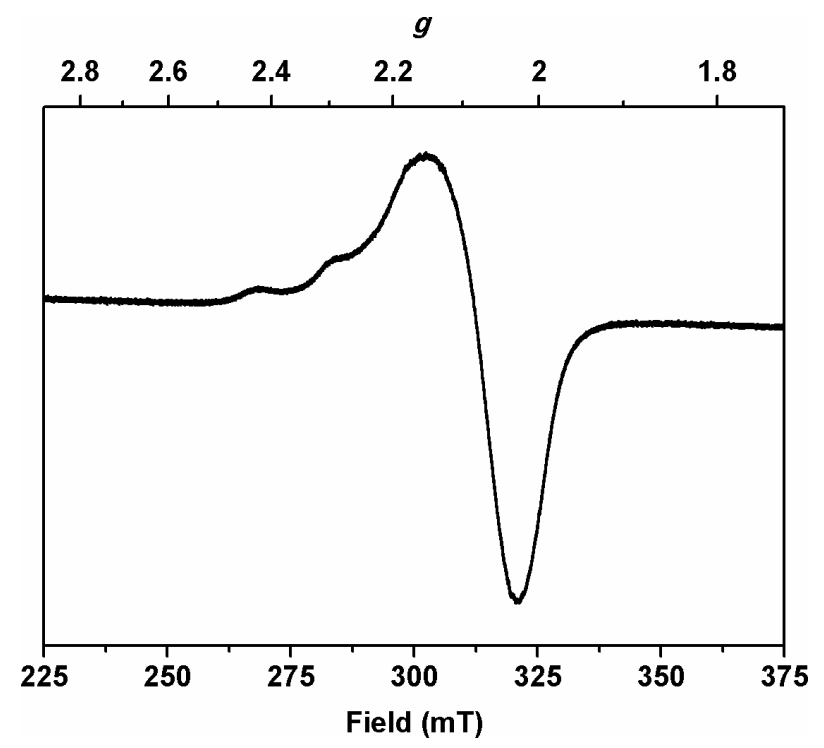

Figure S13. X-band EPR spectrum (Acetonitrile, $77 \mathrm{~K}$ ) of $[\mathrm{mCH}] \mathrm{Cu}\left(\kappa^{2}-\mathrm{O}_{2} \mathrm{~N}\right)\left(\mathrm{ClO}_{4}\right)_{2}(3)$. Data collection parameters: Frequency $=9092.167 \mathrm{MHz}$, Power $=0.995 \mathrm{~mW}$, ModWidth $=0.1 \mathrm{mT}$, time constant $=0.1 \mathrm{~s}$. 


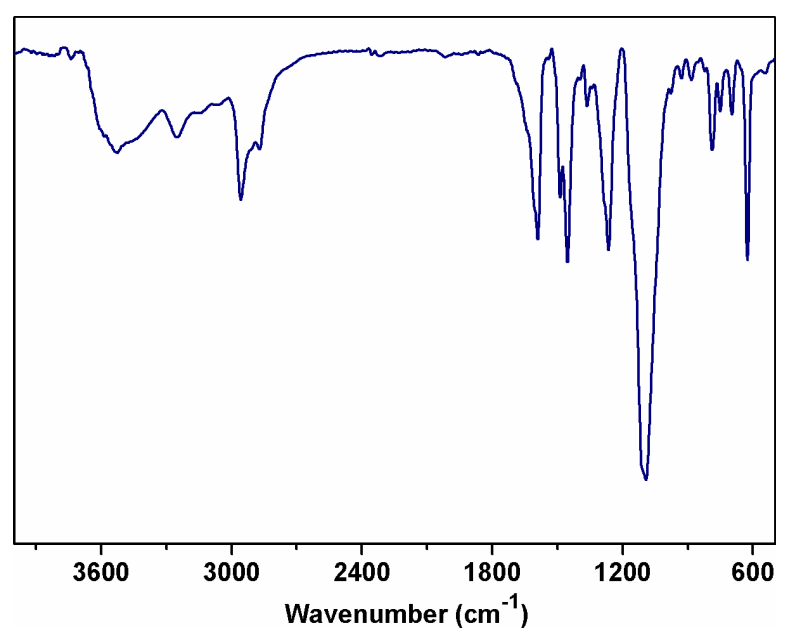

Figure S14. FTIR (KBr pellet) spectrum of $[\mathrm{mCH}] \mathrm{Cu}\left(\kappa^{2}-\mathrm{O}_{2} \mathrm{~N}\right)\left(\mathrm{ClO}_{4}\right)_{2}(3)$.

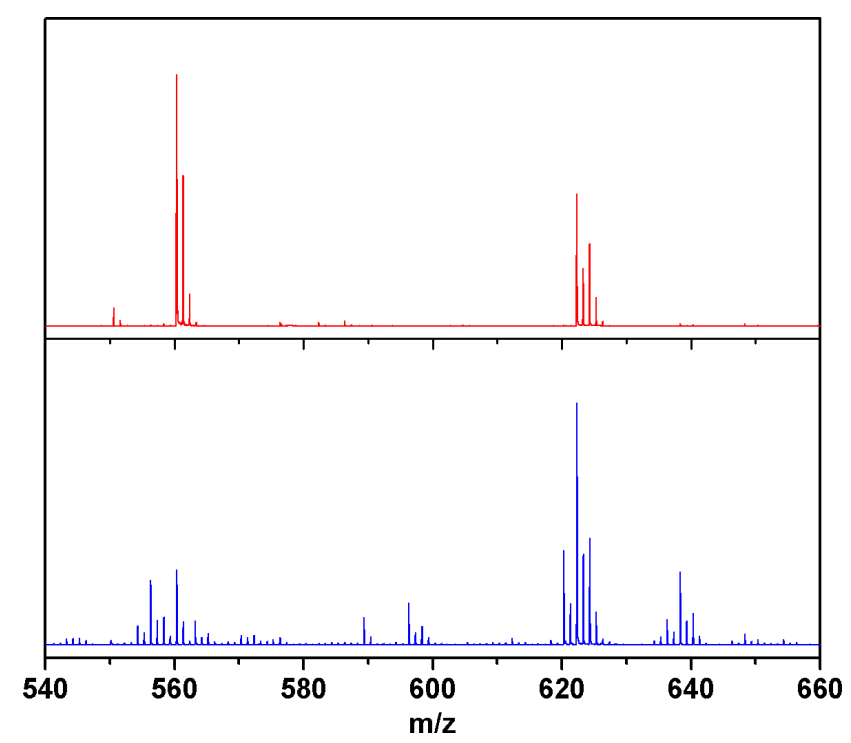

Figure S15. Top: MALDI-TOF spectrum obtained from the solution of $[\mathrm{mC}] \mathrm{Cu}\left(\kappa^{2}-\right.$ $\left.\mathrm{O}_{2} \mathrm{~N}\right)\left(\mathrm{ClO}_{4}\right)$ (1a). Bottom: MALDI-TOF spectrum of the crude reaction mixture obtained after the reaction of $[\mathrm{mC}] \mathrm{Cu}\left(\kappa^{2}-\mathrm{O}_{2} \mathrm{~N}\right)\left(\mathrm{ClO}_{4}\right)$ (1a) with one equivalent of 2,4-DTBP. The $\mathrm{m} / \mathrm{z}$ peaks at $560.6,622.3$, and 638.3 correspond to the respective formulations of $[\mathrm{mC}+\mathrm{H}]^{+}$, $[\mathrm{mCCu}]^{+}$and $[\{[\mathrm{mC}] \mathrm{Cu}(\mathrm{OH})\}-\mathrm{H}]^{+}$. 


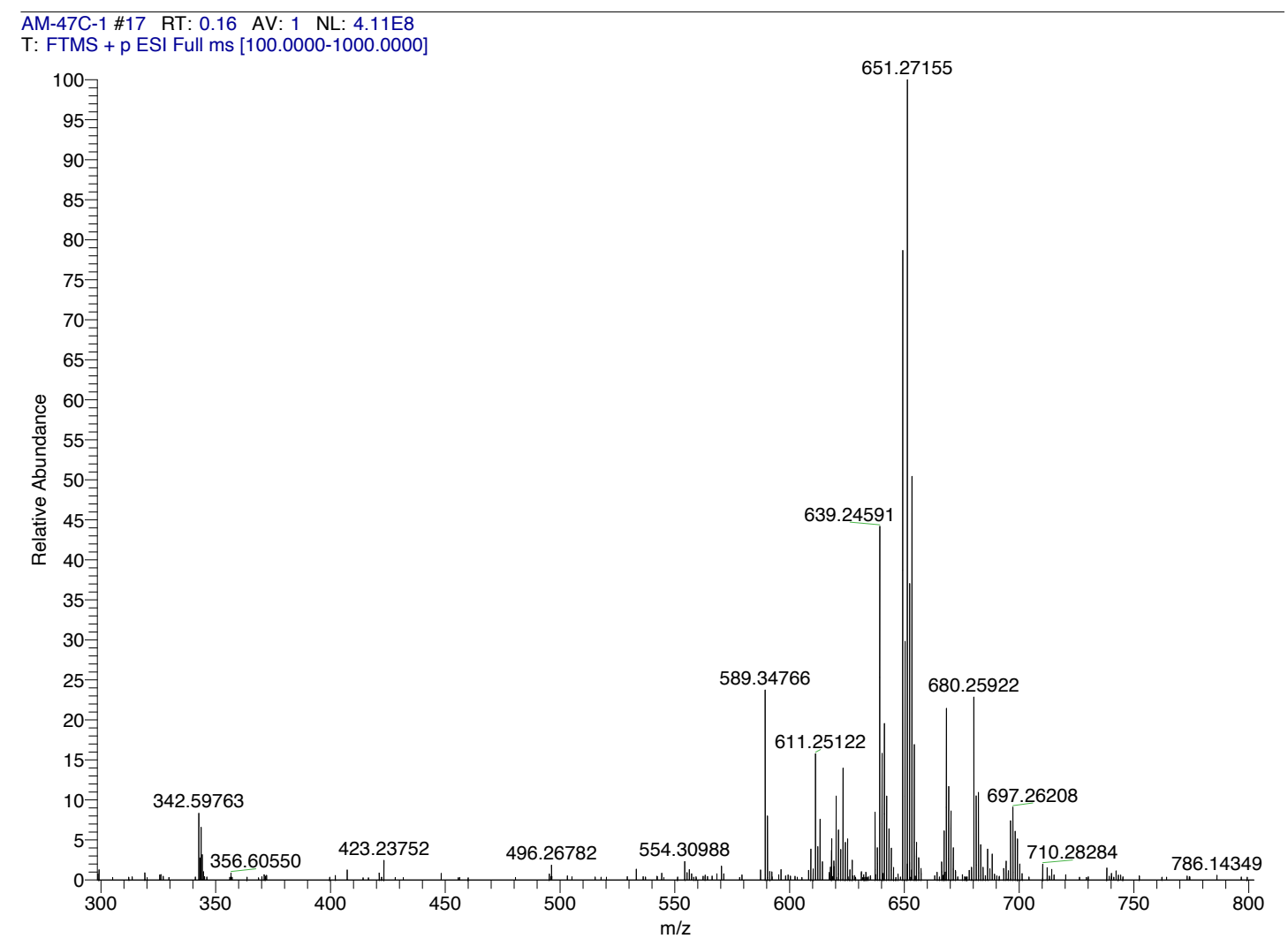

Figure S16. ESI-MS(+) spectrum of the crude reaction mixture obtained after the reaction of $[\mathrm{mC}] \mathrm{Cu}\left(\kappa^{2}-\mathrm{O}_{2} \mathrm{~N}\right)\left(\mathrm{ClO}_{4}\right)(\mathbf{1 a})$ with one equivalent of $2,4-\mathrm{DTBP}$.

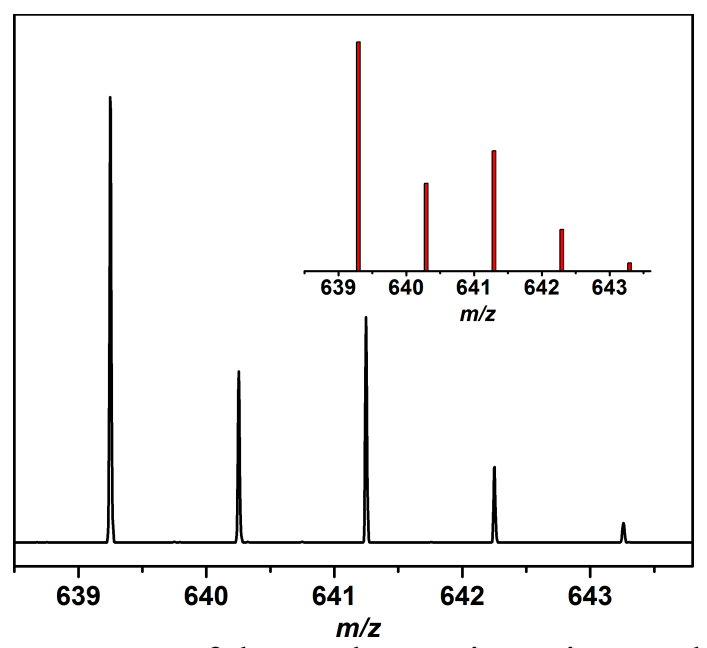

Figure S17. ESI-MS(+) spectrum of the crude reaction mixture obtained after the reaction of $[\mathrm{mC}] \mathrm{Cu}\left(\kappa^{2}-\mathrm{O}_{2} \mathrm{~N}\right)\left(\mathrm{ClO}_{4}\right)$ (1a) with one equivalent of $2,4-\mathrm{DTBP}$. The $\mathrm{m} / \mathrm{z}$ peak at 639.2459 and the isotope distribution pattern corresponds to $\{[\mathrm{mC}] \mathrm{Cu}(\mathrm{OH})\}^{+}$. Inset shows the simulated spectral pattern for $\left\{\mathrm{C}_{33} \mathrm{H}_{46} \mathrm{CuN}_{5} \mathrm{O}_{4}\right\}^{+}$. 


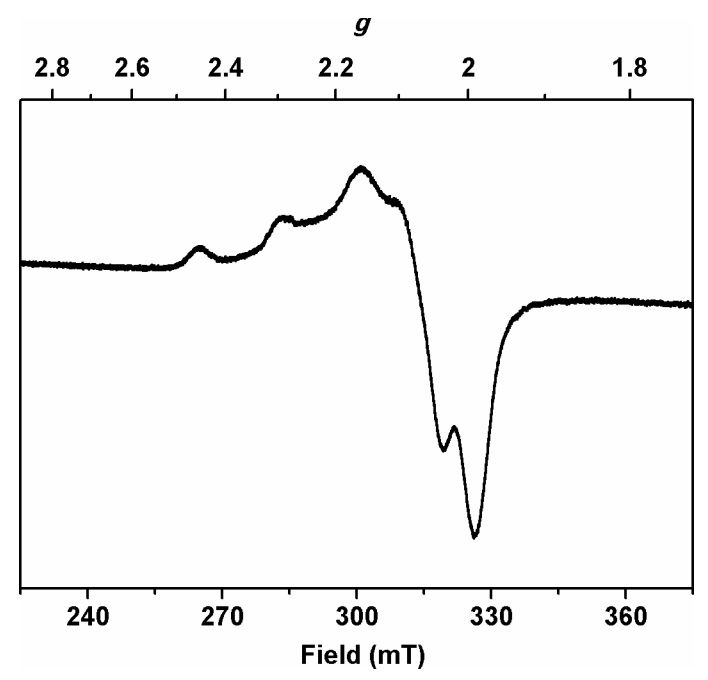

Figure S18. X-band EPR spectrum (Acetonitrile, $77 \mathrm{~K}$ ) of the crude reaction mixture obtained after the reaction of $[\mathrm{mC}] \mathrm{Cu}\left(\kappa^{2}-\mathrm{O}_{2} \mathrm{~N}\right)\left(\mathrm{ClO}_{4}\right)(\mathbf{1 a})$ with one equivalents of 2,4DTBP. Data collection parameters: Frequency $=9092.167 \mathrm{MHz}$, Power $=0.995 \mathrm{~mW}$, ModWidth $=0.1 \mathrm{mT}$, time constant $=0.1 \mathrm{~s}$.

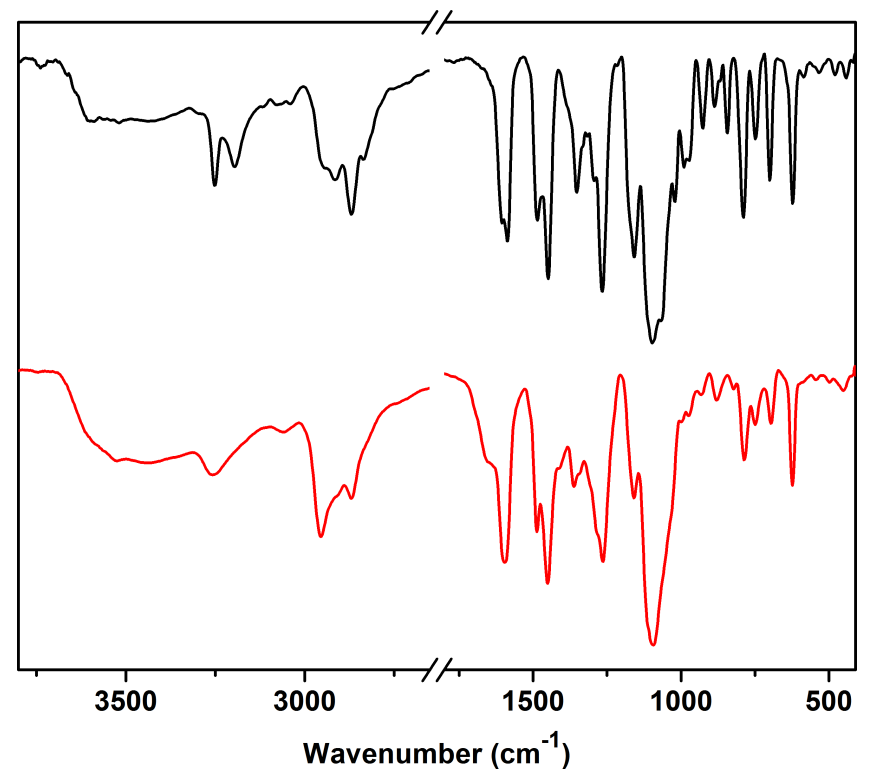

Figure S19. Comparison of the FTIR ( $\mathrm{KBr}$ pellet) spectra of $[\mathrm{mC}] \mathrm{Cu}\left(\kappa^{2}-\mathrm{O}_{2} \mathrm{~N}\right)\left(\mathrm{ClO}_{4}\right)(\mathbf{1 a})$ (black trace) and the copper product obtained from the reaction of $[\mathrm{mC}] \mathrm{Cu}\left(\kappa^{2}-\mathrm{O}_{2} \mathrm{~N}\right)\left(\mathrm{ClO}_{4}\right)$ (1a) with one equivalent of 2,4-DTBP (red trace). 


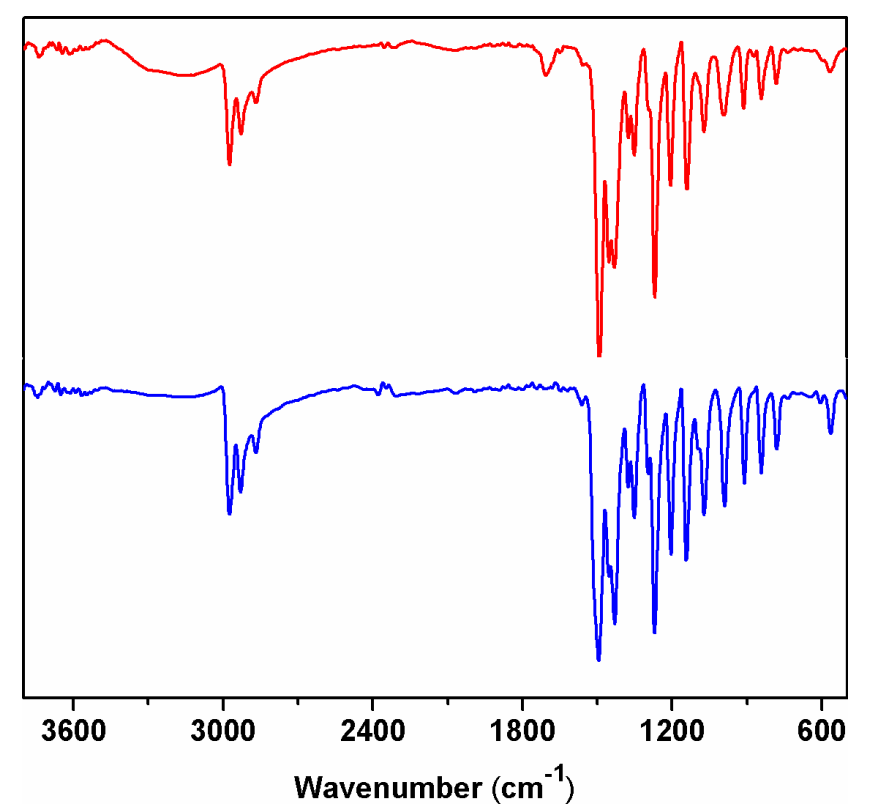

Figure S20. FTIR (KBr pellet) spectrum of (dtc) ${ }_{2} \mathrm{Fe}^{\mathrm{II}} \mathrm{NO}$ (red trace) obtained from the NOtrapping experiment. The FTIR (KBr pellet) spectrum of $(\mathrm{dtc})_{2} \mathrm{Fe}^{\mathrm{II}}$ (blue trace) is shown for comparison. The peak at $1707 \mathrm{~cm}^{-1}$ can be attributed to $v(\mathrm{NO}) .{ }^{\mathrm{S} 11}$

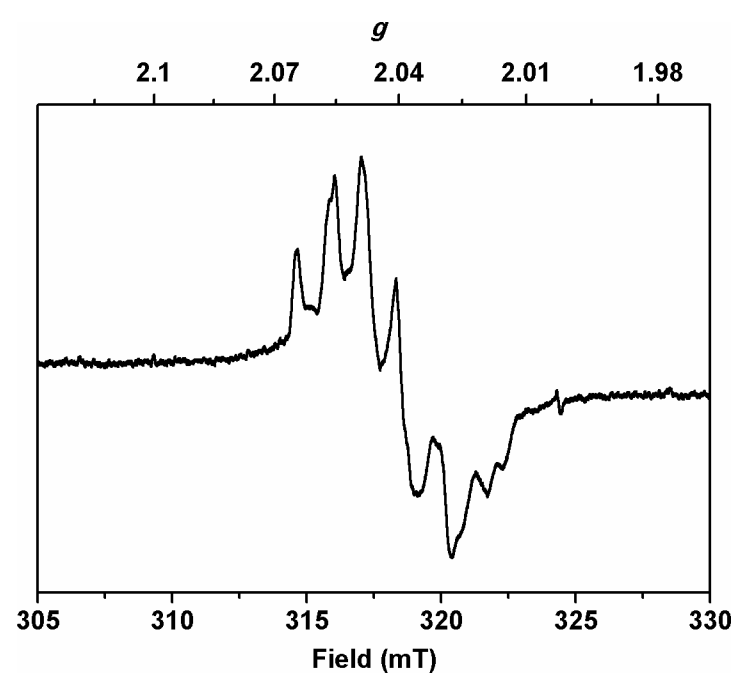

Figure S21. X-band EPR spectrum (Acetonitrile, $77 \mathrm{~K}$ ) of (dtc $)_{2} \mathrm{Fe}(\mathrm{NO})$ obtained from the NO trapping experiment. Data collection parameters: Frequency $=9092.167 \mathrm{MHz}$, Power $=0.995 \mathrm{~mW}$, ModWidth $=0.1 \mathrm{mT}$, time constant $=0.1 \mathrm{~s}$. Similar EPR features of $(\mathrm{dtc})_{2} \mathrm{Fe}(\mathrm{NO})$ has been reported in literature previously. ${ }^{\mathrm{s} 11}$ 


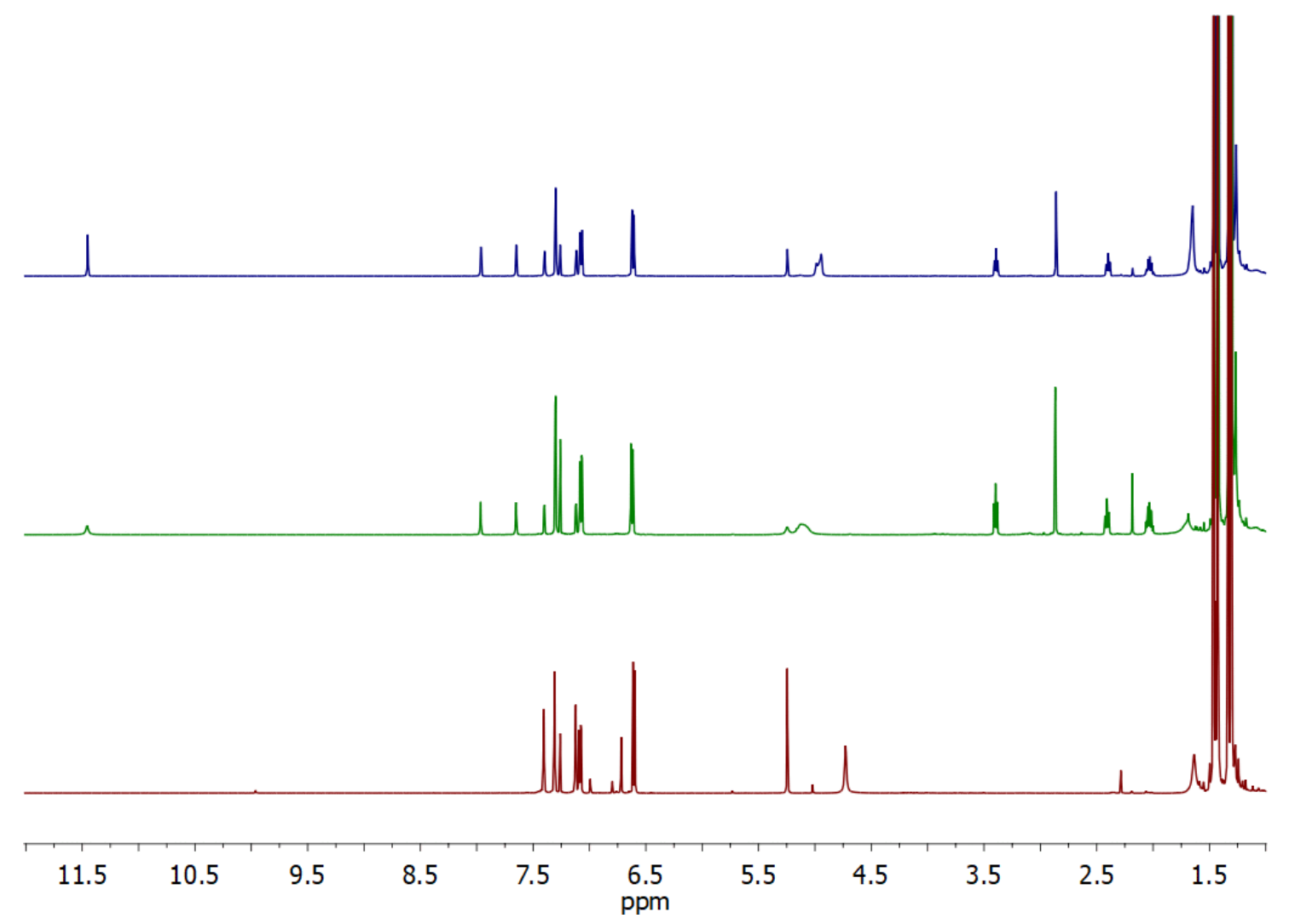

Figure S22. Comparison of the ${ }^{1} \mathrm{H} \mathrm{NMR}\left(500 \mathrm{MHz}, \mathrm{CDCl}_{3}, 298 \mathrm{~K}\right)$ spectra obtained from the reaction mixtures consisting organic product(s) after removal of $\mathrm{Cu}$ product(s). Top trace: $[\mathrm{mCH}] \mathrm{Cu}\left(\kappa^{2}-\mathrm{O}_{2} \mathrm{~N}\right)\left(\mathrm{ClO}_{4}\right)_{2}(3)+2,4-\mathrm{DTBP}+\mathrm{NaNO}_{2}$ (1:1:10); Middle trace: $[\mathrm{mCH}] \mathrm{Cu}\left(\kappa^{2}-\mathrm{O}_{2} \mathrm{~N}\right)\left(\mathrm{ClO}_{4}\right)_{2}(3)+2,4-\mathrm{DTBP}(1: 1)$; and Bottom trace: $[\mathrm{mC}] \mathrm{Cu}\left(\kappa^{2}-\right.$ $\left.\mathrm{O}_{2} \mathrm{~N}\right)\left(\mathrm{ClO}_{4}\right)(\mathbf{1 a})+2,4-\mathrm{DTBP}(1: 1)$. The peak at $11.46 \mathrm{ppm}$ corresponds to the phenolic$\mathrm{OH}$ of 6-nitro-2,4-di-tert-butylphenol (6). 

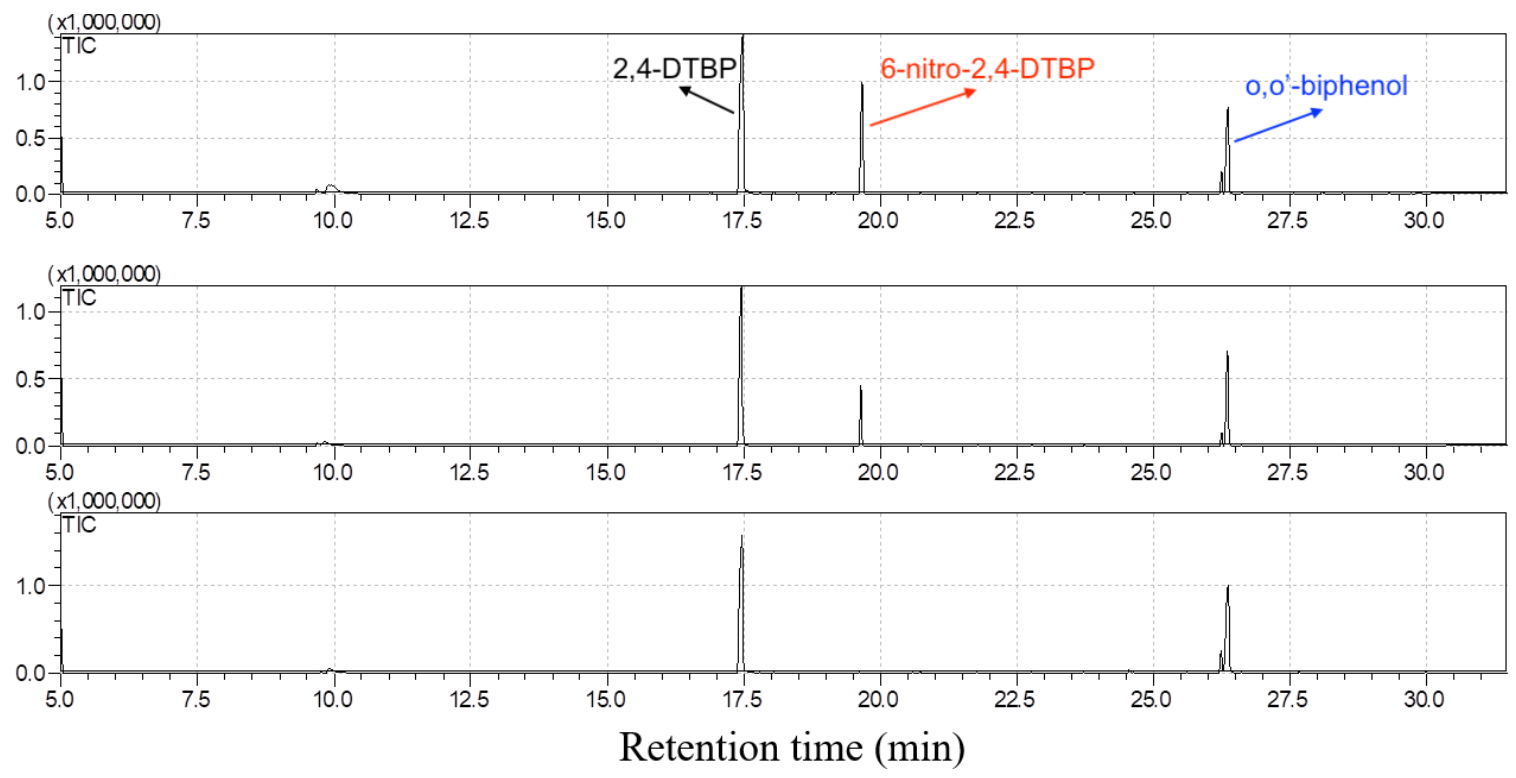

Figure S23. GC-FID profiles obtained from the reaction mixtures consisting organic product(s) after removal of $\mathrm{Cu}$ product(s). Top: $[\mathrm{mCH}] \mathrm{Cu}\left(\kappa^{2}-\mathrm{O}_{2} \mathrm{~N}\right)\left(\mathrm{ClO}_{4}\right)_{2}(3)+2,4-\mathrm{DTBP}$ + $\mathrm{NaNO}_{2}(1: 1: 10)$; Middle: $[\mathrm{mCH}] \mathrm{Cu}\left(\kappa^{2}-\mathrm{O}_{2} \mathrm{~N}\right)\left(\mathrm{ClO}_{4}\right)_{2}(3)+2,4-\mathrm{DTBP}$ (1:1); Bottom: $[\mathrm{mC}] \mathrm{Cu}\left(\kappa^{2}-\mathrm{O}_{2} \mathrm{~N}\right)\left(\mathrm{ClO}_{4}\right)(\mathbf{1 a})+2,4-\mathrm{DTBP}(1: 1)$. The Retention time (min) at 17.44, 19.65 and 26.38 min corresponds to 2,4-DTBP, 6-nitro-2,4-DTBP (6) and $o, o$ '-biphenol of 2,4DTBP (5).
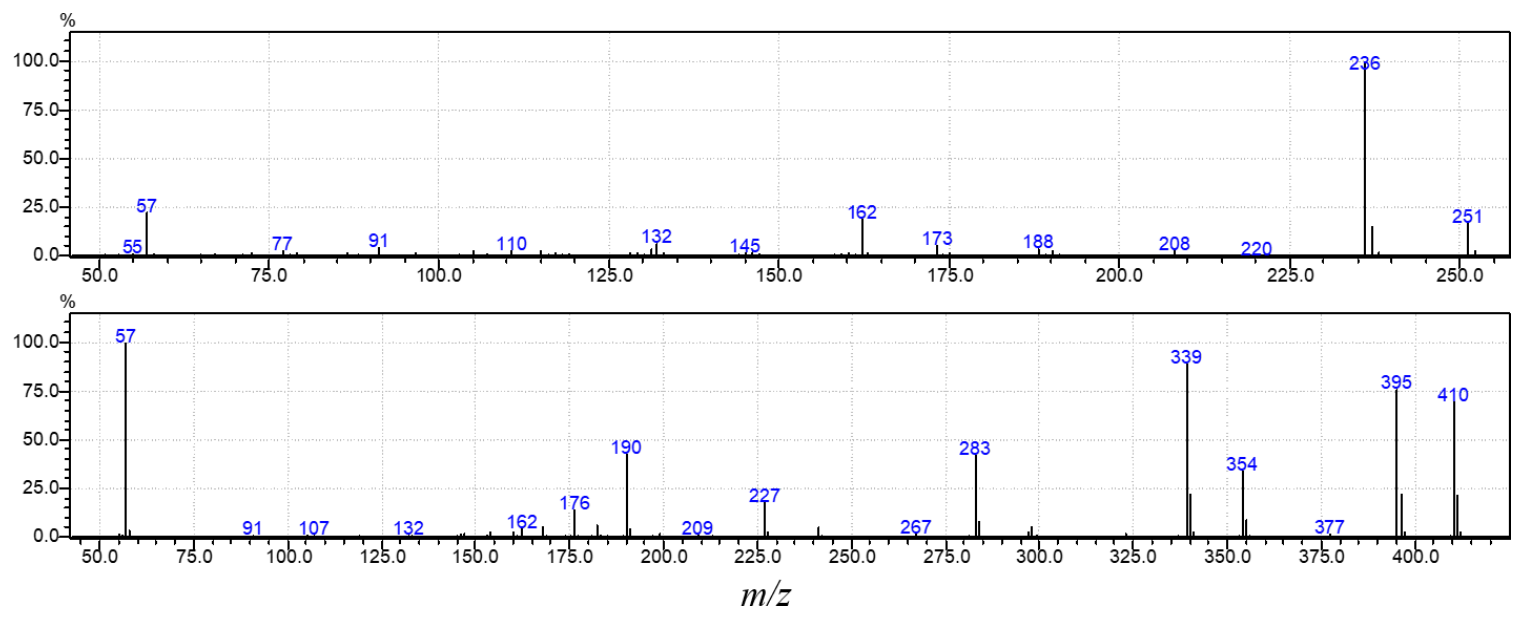

Figure S24. GC/MS-EI mode spectra of 6-nitro-2,4-DTBP $\left(m / z\right.$ calcd for $\mathrm{C}_{14} \mathrm{H}_{21} \mathrm{NO}_{3}[\mathrm{M}]^{+}$ 251.2) (top) and $o, o^{\prime}$-biphenol of 2,4-DTBP (5) $\left(\mathrm{m} / z\right.$ calcd for $\left.\mathrm{C}_{28} \mathrm{H}_{42} \mathrm{O}_{2}[\mathrm{M}]^{+} 410.3\right)$ (bottom). 


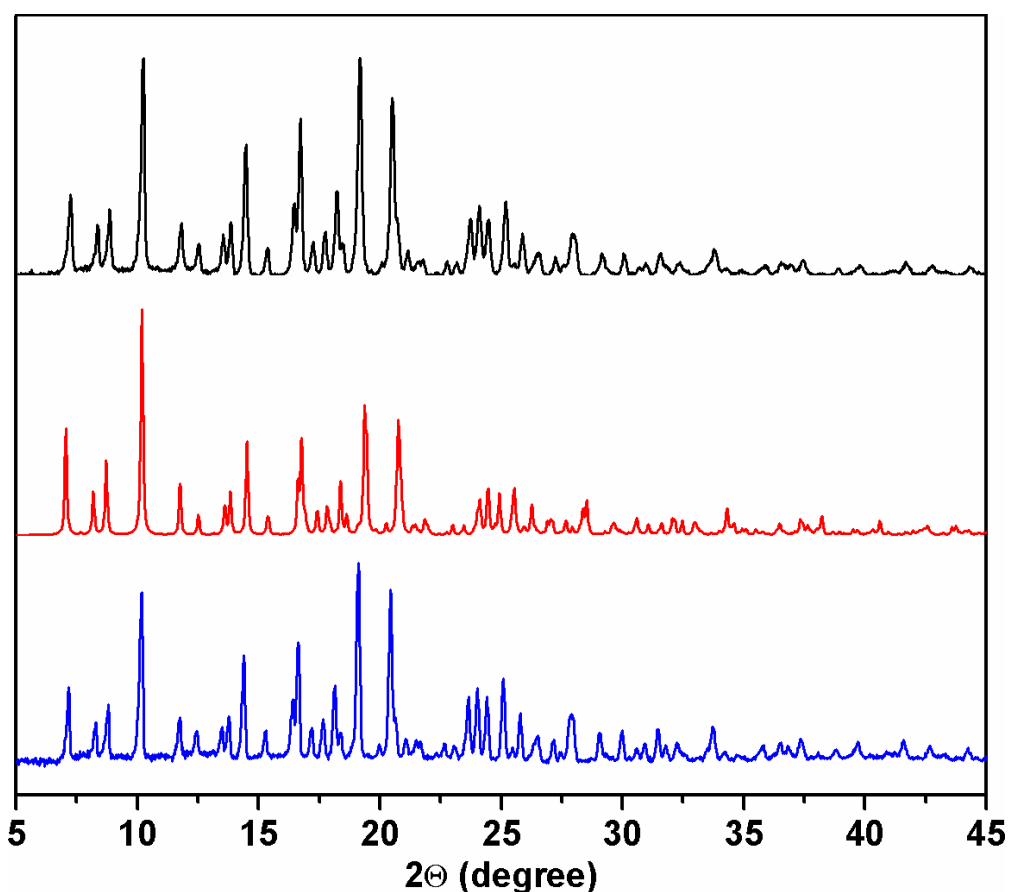

Figure S25. Comparison of the PXRD patterns of $[\mathrm{mC}] \mathrm{Zn}\left(\kappa^{2}-\mathrm{O}_{2} \mathrm{~N}\right)\left(\mathrm{ClO}_{4}\right)$ (1) $)$ (black trace), simulated (red trace), and after the reaction of $[\mathrm{mC}] \mathrm{Zn}\left(\kappa^{2}-\mathrm{O}_{2} \mathrm{~N}\right)\left(\mathrm{ClO}_{4}\right)(\mathbf{1 b})$ with ten equivalent 2,4-DTBP (blue trace). 

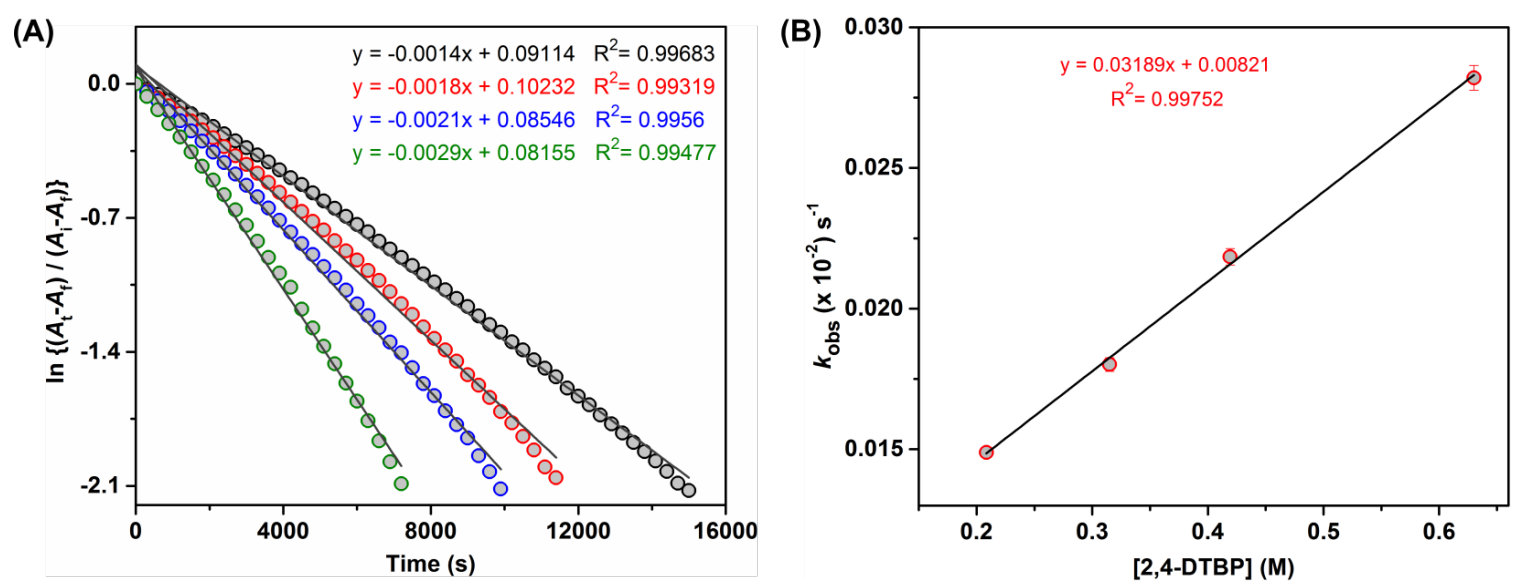

Figure S26. (A) $\ln \left\{\left(A_{\mathrm{t}}-A_{\mathrm{f}}\right) /\left(A_{\mathrm{i}}-A_{\mathrm{f}}\right)\right\}$ versus time plots for the reactions of $[\mathrm{mC}] \mathrm{Cu}\left(\kappa^{2}-\right.$ $\left.\mathrm{O}_{2} \mathrm{~N}\right)\left(\mathrm{ClO}_{4}\right)$ (1a) with different equivalents of 2,4-di-tert-butylphenol (2,4-DTBP). Reaction conditions: Initial concentration of $\mathbf{1 a}=2.0 \mathrm{mM}$ in acetonitrile, Initial concentrations of 2,4-DTBP $=0.21,0.32,0.42$, and $0.63 \mathrm{M}$, Temperature $=65{ }^{\circ} \mathrm{C}$. The slope of the $\ln \left\{\left(A_{\mathrm{t}}-A_{\mathrm{f}}\right) /\left(A_{\mathrm{i}}-A_{\mathrm{f}}\right)\right\}$ versus time plots provide the pseudo-first-order rate constant $\left(k_{\text {obs }}\right)$ for a particular concentration of 2,4-DTBP. (B) Pseudo-first-order rate constant $\left(k_{\mathrm{obs}}\right)$ versus concentration of 2,4-DTBP plot. The positive intercept at zero substrate concentration presumably arises from a slow self-decomposition of $\mathbf{1 a}$ at $65{ }^{\circ} \mathrm{C}$.
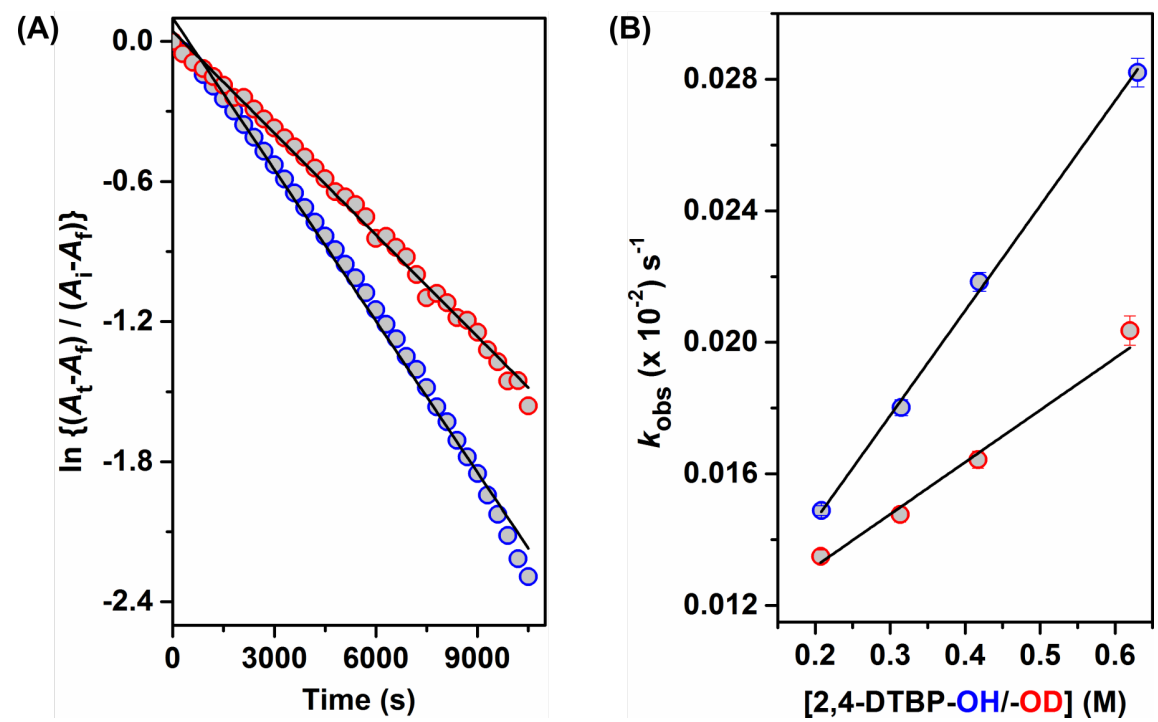

Figure S27. (A) Comparison of $\ln \left\{\left(A_{\mathrm{t}}-A_{\mathrm{f}}\right) /\left(A_{\mathrm{i}}-A_{\mathrm{f}}\right)\right\}$ versus time plots for the reaction of $[\mathrm{mC}] \mathrm{Cu}\left(\kappa^{2}-\mathrm{O}_{2} \mathrm{~N}\right)\left(\mathrm{ClO}_{4}\right)$ (1a) with 2,4-di-tert-butylphenol (2,4-DTBP) (Blue circle) and 
2,4-di-tert-butylphenol-OD (2,4-DTBP-OD) (Red circle). Reaction conditions: Initial concentration of $1 \mathbf{a}=2.0 \mathrm{mM}$ in acetonitrile, Initial concentrations of 2,4-DTBP-OH/-OD $=0.21 \mathrm{M} \mathrm{(} \mathrm{200} \mathrm{equivalents} \mathrm{w.r.t.} \mathrm{1a),} \mathrm{Temperature}=65^{\circ} \mathrm{C}$. (B) Comparison of pseudofirst-order rate constant $\left(k_{\mathrm{obs}}\right)$ versus concentration of 2,4-DTBP-OH (blue circles)/-OD (red circles) plots.
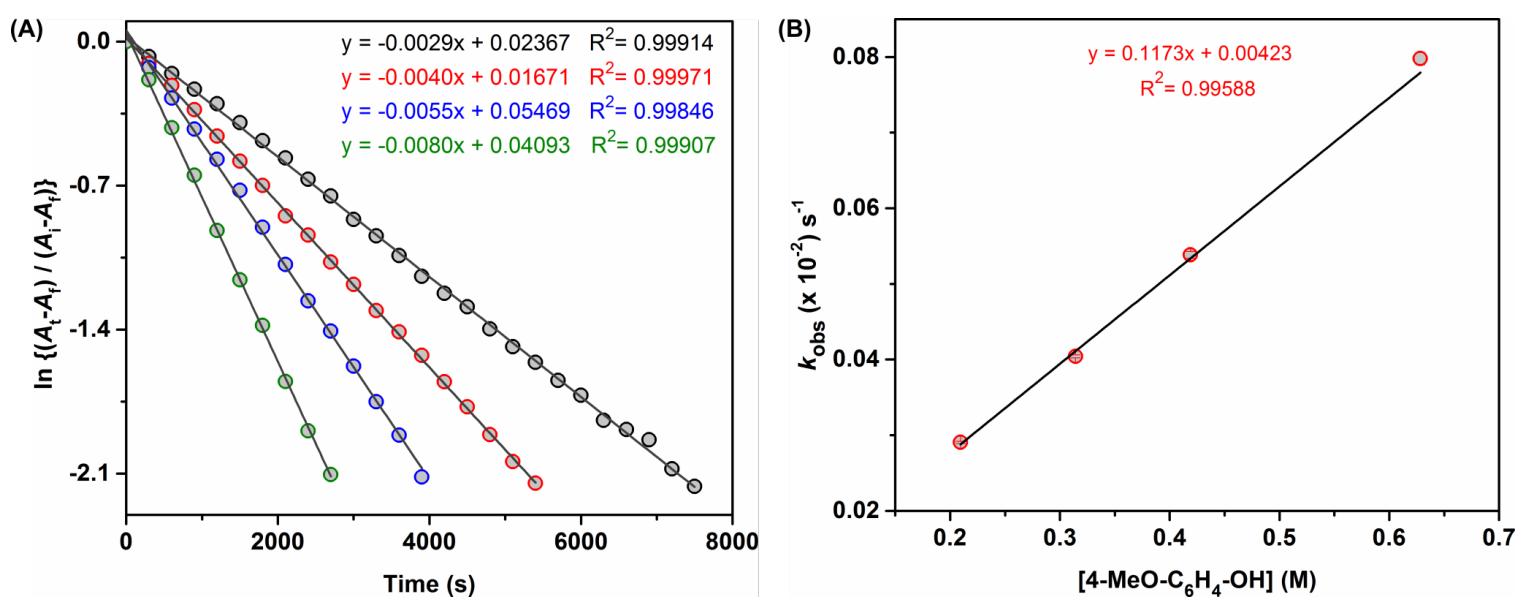

Figure S28. (A) $\ln \left\{\left(A_{\mathrm{t}}-A_{\mathrm{f}}\right) /\left(A_{\mathrm{i}}-A_{\mathrm{f}}\right)\right\}$ versus time plots for the reactions of $[\mathrm{mC}] \mathrm{Cu}\left(\kappa^{2}-\right.$ $\left.\mathrm{O}_{2} \mathrm{~N}\right)\left(\mathrm{ClO}_{4}\right)$ (1a) with different equivalents of 4-methoxyphenol (4-MeO- $\left.\mathrm{C}_{6} \mathrm{H}_{4}-\mathrm{OH}\right)$. Reaction conditions: Initial concentration of $\mathbf{1 a}=2.0 \mathrm{mM}$ in acetonitrile, Initial concentrations of 4-MeO- $\mathrm{C}_{6} \mathrm{H}_{4}-\mathrm{OH}=0.21,0.31,0.42$, and $0.63 \mathrm{M}$, Temperature $=65^{\circ} \mathrm{C}$. The slope of the $\ln \left\{\left(A_{\mathrm{t}}-A_{\mathrm{f}}\right) /\left(A_{\mathrm{i}}-A_{\mathrm{f}}\right)\right\}$ versus time plots provide the pseudo-first-order rate constant $\left(k_{\mathrm{obs}}\right)$ for a particular concentration of 4-MeO- $\mathrm{C}_{6} \mathrm{H}_{4}-\mathrm{OH}$. (B) Pseudo-first-order rate constant $\left(k_{\text {obs }}\right)$ versus concentration of $4-\mathrm{MeO}-\mathrm{C}_{6} \mathrm{H}_{4}-\mathrm{OH}$ plot. The positive intercept at zero substrate concentration presumably arises from a slow self-decomposition of $1 \mathbf{a}$ at 65 ${ }^{\circ} \mathrm{C}$. 

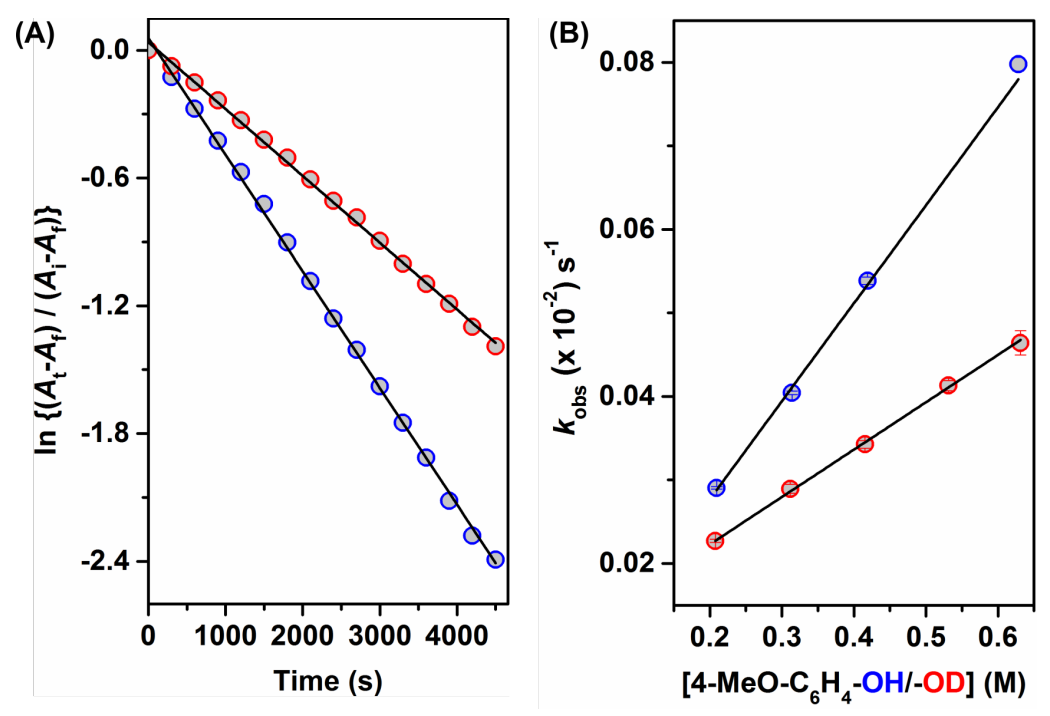

Figure S29. (A) Comparison of $\ln \left\{\left(A_{\mathrm{t}}-A_{\mathrm{f}}\right) /\left(A_{\mathrm{i}}-A_{\mathrm{f}}\right)\right\}$ versus time plots for the reaction of $[\mathrm{mC}] \mathrm{Cu}\left(\kappa^{2}-\mathrm{O}_{2} \mathrm{~N}\right)\left(\mathrm{ClO}_{4}\right)(\mathbf{1 a})$ with 4-methoxyphenol (4-MeO- $\left.\mathrm{C}_{6} \mathrm{H}_{4}-\mathrm{OH}\right)$ (Blue circle) and 4-methoxyphenol-OD (4-MeO- $\left.\mathrm{C}_{6} \mathrm{H}_{4}-\mathrm{OD}\right)$ (Red circle). Reaction conditions: Initial concentration of $\mathbf{1 a}=2.0 \mathrm{mM}$ in acetonitrile, Initial concentrations of 4-MeO- $\mathrm{C}_{6} \mathrm{H}_{4}-\mathrm{OH} /-$ $\mathrm{OD}=0.42 \mathrm{M}\left(\sim 200\right.$ equivalents w.r.t. 1a), Temperature $=65{ }^{\circ} \mathrm{C}$. (B) Comparison of pseudo-first-order rate constant $\left(k_{\mathrm{obs}}\right)$ versus concentration of $4-\mathrm{MeO}-\mathrm{C}_{6} \mathrm{H}_{4}-\mathrm{OH}$ (blue circles)/-OD (red circles) plots.

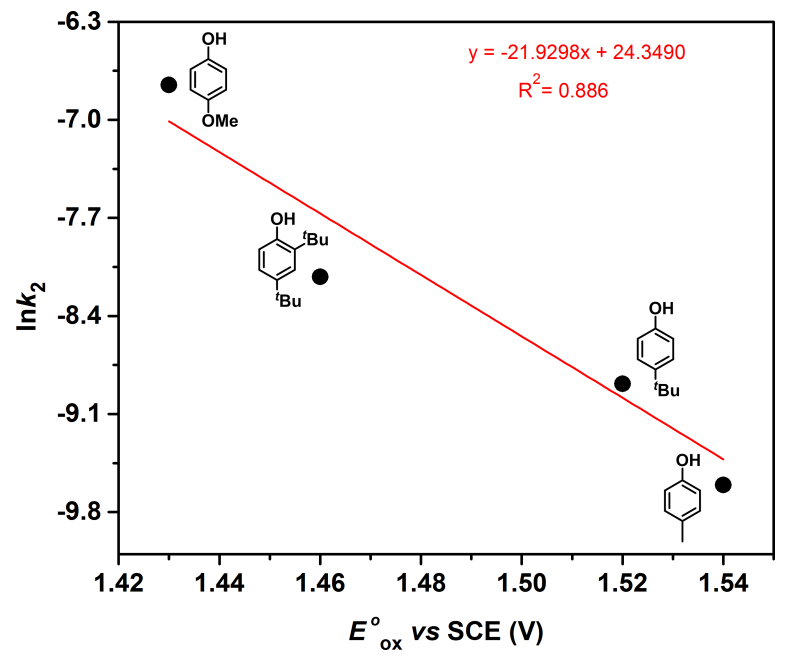

Figure S30. Plot of $\ln k_{2}$ versus $E_{\text {ox }}$ for the reaction of $[\mathrm{mC}] \mathrm{Cu}\left(\kappa^{2}-\mathrm{O}_{2} \mathrm{~N}\right)\left(\mathrm{ClO}_{4}\right)(1 \mathrm{a})$ with different phenols against the one electron oxidation potential $\left(E_{\mathrm{ox}}\right)$ of the respective phenol. $E_{\text {ox }}$ values of the substituted phenols were taken from the previously reported literature. ${ }^{\mathrm{S} 12}$ 


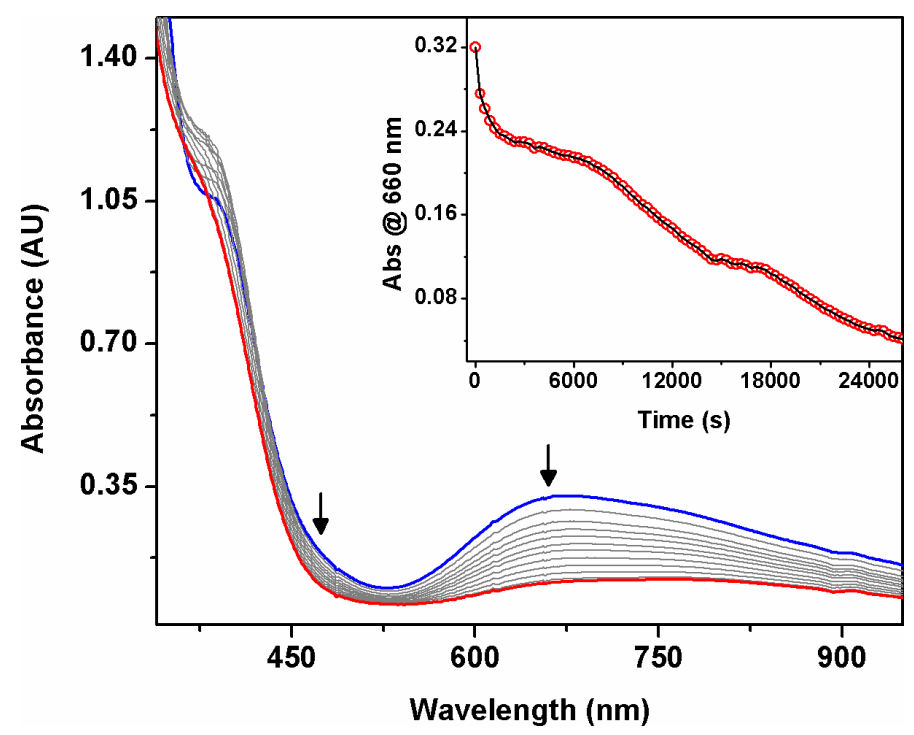

Figure S31. Changes in the absorption features of $[\mathrm{mCH}] \mathrm{Cu}\left(\kappa^{2}-\mathrm{O}_{2} \mathrm{~N}\right)\left(\mathrm{ClO}_{4}\right)_{2}(3)(2.0 \mathrm{mM})$ upon addition of 2,4-DTBP $\left(0.17 \mathrm{M}, 85\right.$ equivalents w.r.t. 3) in acetonitrile at $65^{\circ} \mathrm{C}$. The inset shows the decay profile of the $660 \mathrm{~nm}$ band.

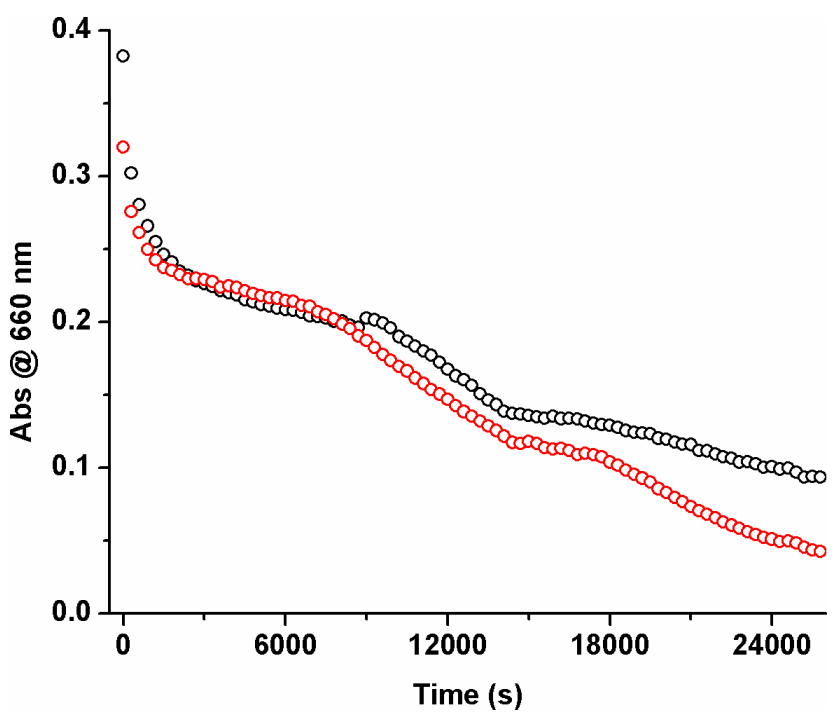

Figure S32. Comparison of the UV-Vis time traces as monitored for the decay of $660 \mathrm{~nm}$ feature during the reactions $[\mathrm{mCH}] \mathrm{Cu}\left(\kappa^{2}-\mathrm{O}_{2} \mathrm{~N}\right)\left(\mathrm{ClO}_{4}\right)_{2}(3)$ with 2,4-DTBP-OH (red trace) and 2,4-DTBP-OD (black trace) $\left(0.17 \mathrm{M}, 85\right.$ equivalents w.r.t. 3) in acetonitrile at $65^{\circ} \mathrm{C}$. 


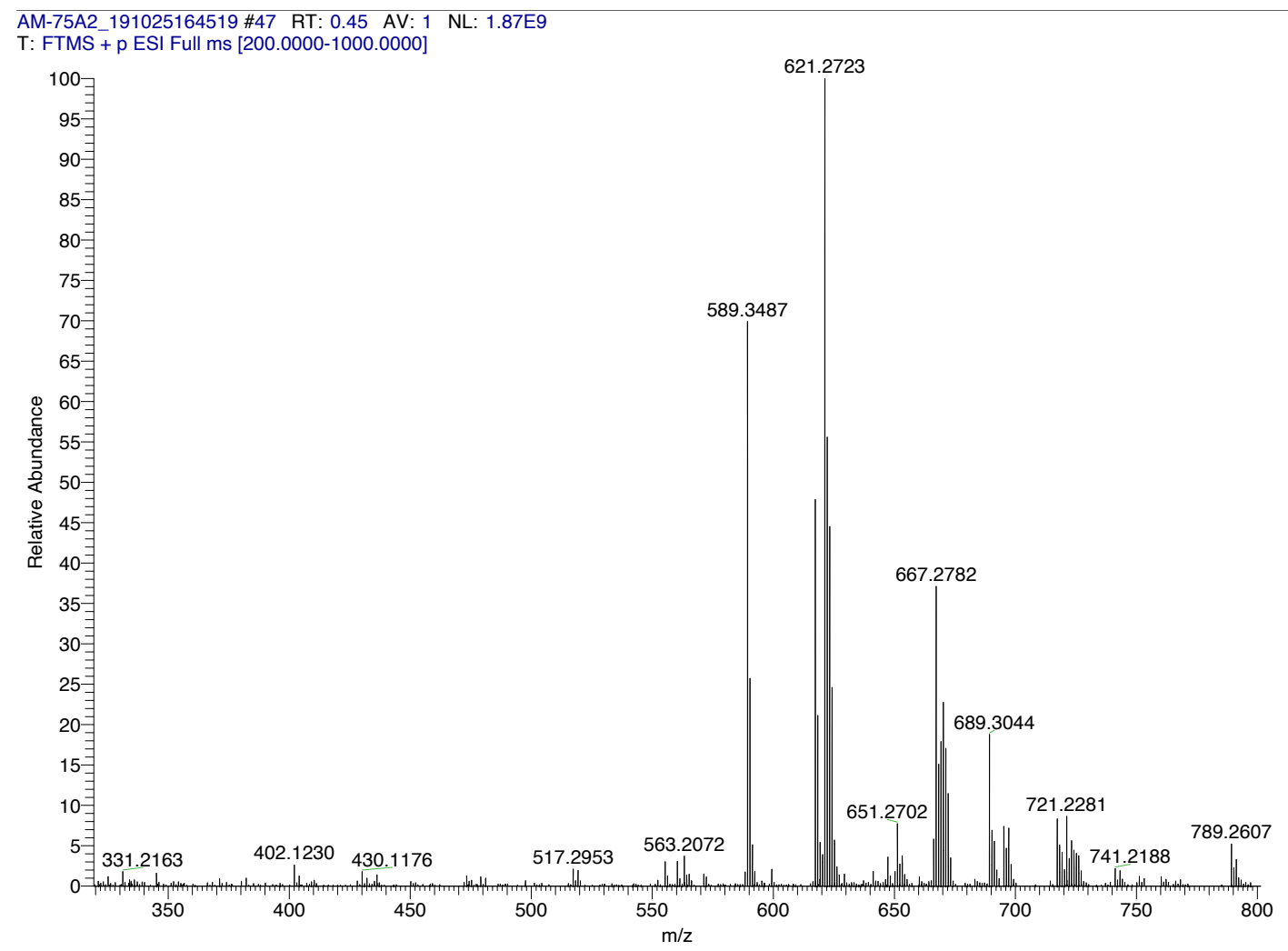

Figure S33. ESI-MS(+) spectrum of the crude reaction mixture obtained after the reaction of $[\mathrm{mCH}] \mathrm{Cu}\left(\kappa^{2}-\mathrm{O}_{2} \mathrm{~N}\right)\left(\mathrm{ClO}_{4}\right)_{2}(3)$ with one equivalent of $2,4-\mathrm{DTBP}$.

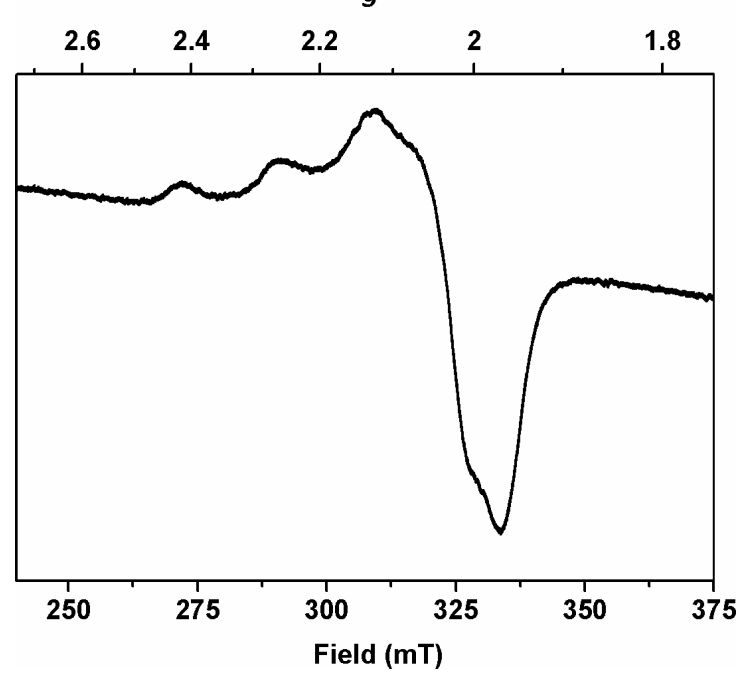

Figure S34. X-band EPR spectrum (Acetonitrile, $77 \mathrm{~K}$ ) of the crude reaction mixture obtained after the reaction of $[\mathrm{mCH}] \mathrm{Cu}\left(\kappa^{2}-\mathrm{O}_{2} \mathrm{~N}\right)\left(\mathrm{ClO}_{4}\right)_{2}(3)$ with one equivalent of 2,4DTBP. Data collection parameters: Frequency $=9092.167 \mathrm{MHz}$, Power $=0.995 \mathrm{~mW}$, ModWidth $=0.1 \mathrm{mT}$, time constant $=0.1 \mathrm{~s}$. 


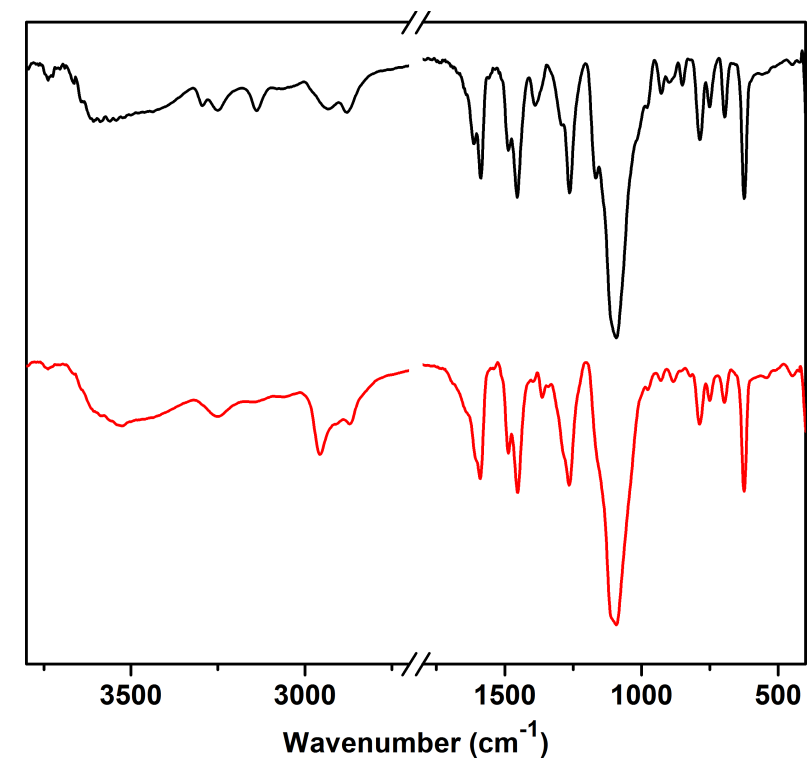

Figure S35. Comparison of the FTIR ( $\mathrm{KBr}$ pellet) spectra of $[\mathrm{mCH}] \mathrm{Cu}\left(\kappa^{2}-\mathrm{O}_{2} \mathrm{~N}\right)\left(\mathrm{ClO}_{4}\right)_{2}$ (3) (black trace) and the copper product obtained from the reaction of $[\mathrm{mCH}] \mathrm{Cu}\left(\kappa^{2}-\right.$ $\left.\mathrm{O}_{2} \mathrm{~N}\right)\left(\mathrm{ClO}_{4}\right)_{2}(3)$ with one equivalent of 2,4-DTBP (red trace).

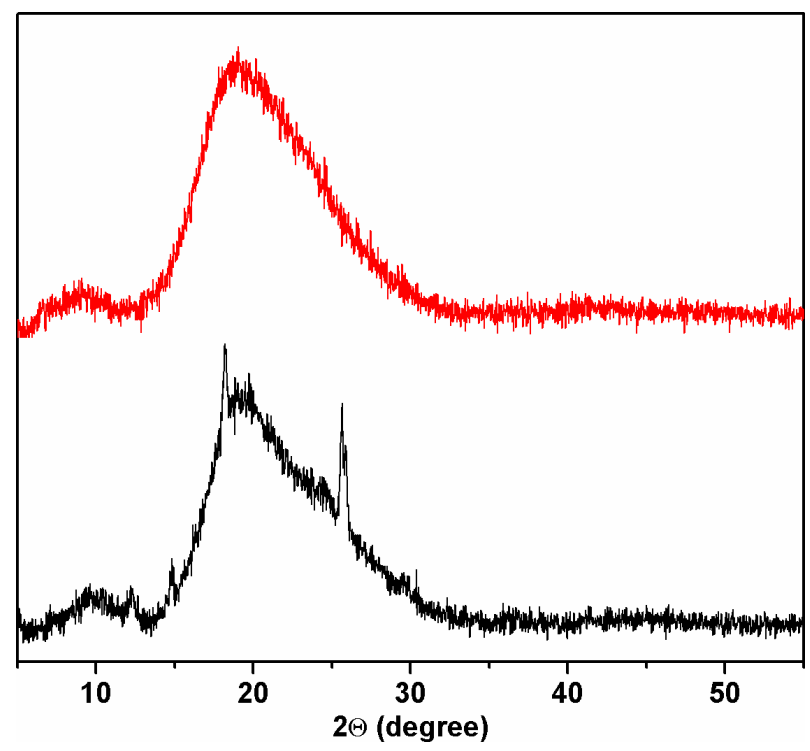

Figure S36. Comparison of the PXRD patterns of the copper products obtained from the 2,4-DTBP (1.0 equiv) reactions with $[\mathrm{mCH}] \mathrm{Cu}\left(\kappa^{2}-\mathrm{O}_{2} \mathrm{~N}\right)\left(\mathrm{ClO}_{4}\right)_{2}(3)$ (black trace) and with $[\mathrm{mC}] \mathrm{Cu}\left(\kappa^{2}-\mathrm{O}_{2} \mathrm{~N}\right)\left(\mathrm{ClO}_{4}\right)(\mathbf{1 a})($ red trace $)$. 


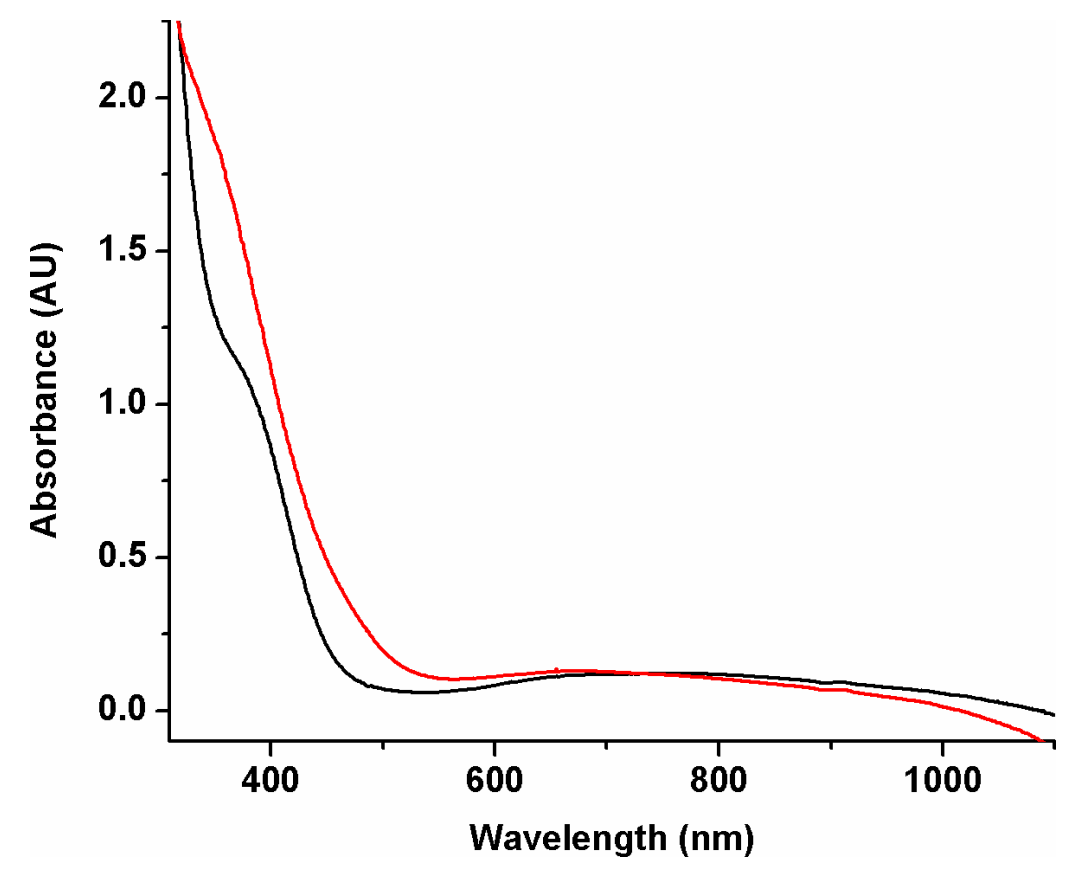

Figure S37. Comparison of the UV-Vis spectra of the crude reaction mixtures obtained after the reactions of $[\mathrm{mC}] \mathrm{Cu}\left(\kappa^{2}-\mathrm{O}_{2} \mathrm{~N}\right)\left(\mathrm{ClO}_{4}\right)$ (1a) (red trace) and $[\mathrm{mCH}] \mathrm{Cu}\left(\kappa^{2}-\right.$ $\left.\mathrm{O}_{2} \mathrm{~N}\right)\left(\mathrm{ClO}_{4}\right)_{2}(3)$ (black trace) with 150 equiv of 2,4-DTBP (in acetonitrile at $65^{\circ} \mathrm{C}$ ). 
Table S1. Comparison of bond lengths (in $\AA$ ) and angles (in $\left.{ }^{\circ}\right)$ for $[\mathrm{mC}] \mathrm{Cu}\left(\kappa^{2}-\right.$ $\left.\mathrm{O}_{2} \mathrm{~N}\right)\left(\mathrm{ClO}_{4}\right)(\mathbf{1 a}),[\mathrm{mC}] \mathrm{Zn}\left(\kappa^{2}-\mathrm{O}_{2} \mathrm{~N}\right)\left(\mathrm{ClO}_{4}\right)(\mathbf{1 b})$, and $[\mathrm{mCH}] \mathrm{Cu}\left(\kappa^{2}-\mathrm{O}_{2} \mathrm{~N}\right)\left(\mathrm{ClO}_{4}\right)_{2}(\mathbf{3})$.

\begin{tabular}{|c|c|c|c|}
\hline & $1 \mathrm{a}$ & 1b & 3 \\
\hline $\mathrm{Cu} / \mathrm{Zn} 1-\mathrm{N} 1$ & $2.0302(14)$ & $2.135(3)$ & $2.046(4)$ \\
\hline $\mathrm{Cu} / \mathrm{Zn} 1-\mathrm{N} 2$ & $2.0767(15)$ & $2.212(3)$ & $2.092(4)$ \\
\hline $\mathrm{Cu} / \mathrm{Zn} 1-\mathrm{N} 3$ & $2.2358(15)$ & $2.080(3)$ & $2.227(3)$ \\
\hline $\mathrm{Cu} / \mathrm{Zn} 1-\mathrm{N} 4$ & $2.0566(15)$ & $2.213(3)$ & $2.098(4)$ \\
\hline $\mathrm{Cu} / \mathrm{Zn} 1-\mathrm{O} 4$ & $1.9570(12)$ & $2.041(2)$ & $1.963(3)$ \\
\hline O4-N6 & $1.280(2)$ & $1.277(4)$ & $1.299(4)$ \\
\hline N6-O5 & $1.230(2)$ & $1.253(4)$ & $1.237(4)$ \\
\hline $\mathrm{Cu} / \mathrm{Zn} 1 \cdots \mathrm{O} 5$ & 2.626 & $2.437(2)$ & 2.754 \\
\hline $\mathrm{O} 4 \cdots \mathrm{N} 5$ & 5.241 & 5.012 & 4.575 \\
\hline $\mathrm{N} 1-\mathrm{Cu} / \mathrm{Zn} 1-\mathrm{N} 2$ & $85.35(6)$ & $81.77(11)$ & $85.35(14)$ \\
\hline $\mathrm{N} 2-\mathrm{Cu} / \mathrm{Zn} 1-\mathrm{N} 3$ & $96.80(6)$ & $98.73(12)$ & $109.32(15)$ \\
\hline $\mathrm{N} 3-\mathrm{Cu} / \mathrm{Zn} 1-\mathrm{N} 4$ & $104.00(6)$ & $104.20(12)$ & $107.29(14)$ \\
\hline $\mathrm{N} 4-\mathrm{Cu} / \mathrm{Zn} 1-\mathrm{N} 2$ & $155.84(6)$ & $149.47(11)$ & $140.62(14)$ \\
\hline $\mathrm{N} 1-\mathrm{Cu} / \mathrm{Zn} 1-\mathrm{N} 3$ & $83.88(6)$ & $84.10(12)$ & $83.06(13)$ \\
\hline $\mathrm{N} 1-\mathrm{Cu} / \mathrm{Zn} 1-\mathrm{N} 4$ & $84.79(6)$ & $80.84(11)$ & $85.09(14)$ \\
\hline $\mathrm{N} 1-\mathrm{Cu} / \mathrm{Zn} 1-\mathrm{O} 4$ & $167.62(6)$ & $159.87(11)$ & $174.18(13)$ \\
\hline O4-N6-O5 & $114.01(14)$ & $113.1(3)$ & $114.4(4)$ \\
\hline
\end{tabular}


Table S2. Pseudo-first-order rate constant $\left(k_{\mathrm{obs}}\right)$ and second order rate constants $\left(k_{2}\right)$ for the reaction of $[\mathrm{mC}] \mathrm{Cu}\left(\kappa^{2}-\mathrm{O}_{2} \mathrm{~N}\right)\left(\mathrm{ClO}_{4}\right)(\mathbf{1 a})$ with substituted phenols in acetonitrile at 65 ${ }^{\circ} \mathrm{C}$.

\begin{tabular}{|c|c|c|c|c|c|}
\hline Substrate & conc. (M) & $k_{\text {obs }}\left(\mathrm{s}^{-1}\right)$ & Std. error & $\begin{array}{c}\boldsymbol{k}_{\mathbf{2}} \\
11.73 \times 10^{-4}\end{array}$ & Std. error \\
\hline \multirow{4}{*}{$\mathrm{OMe}$} & 0.20944 & $2.904 \times 10^{-4}$ & $1.4935 \times 10^{-6}$ & \multirow[t]{4}{*}{$11.73 \times 10^{-4}$} & \multirow[t]{4}{*}{$4.35 \times 10^{-5}$} \\
\hline & 0.31416 & $4.042 \times 10^{-4}$ & $2.03704 \times 10^{-6}$ & & \\
\hline & 0.41888 & $5.385 \times 10^{-4}$ & $4.44991 \times 10^{-6}$ & & \\
\hline & 0.62832 & $7.977 \times 10^{-4}$ & $8.10498 \times 10^{-6}$ & & \\
\hline \multirow{5}{*}{$\mathrm{OMe}$} & 0.20775 & $2.271 \times 10^{-4}$ & $1.99157 \times 10^{-6}$ & \multirow[t]{5}{*}{$5.67 \times 10^{-4}$} & \multirow[t]{5}{*}{$7.98 \times 10^{-6}$} \\
\hline & 0.31163 & $2.894 \times 10^{-4}$ & $5.26764 \times 10^{-6}$ & & \\
\hline & 0.4155 & $3.426 \times 10^{-4}$ & $4.61423 \times 10^{-6}$ & & \\
\hline & 0.53136 & $4.130 \times 10^{-4}$ & $6.17703 \times 10^{-6}$ & & \\
\hline & 0.63124 & $4.641 \times 10^{-4}$ & $1.465 \times 10^{-6}$ & & \\
\hline \multirow{4}{*}{${ }^{t} \mathrm{Bu}$} & 0.20841 & $1.4885 \times 10^{-4}$ & $1.4389 \times 10^{-6}$ & \multirow[t]{4}{*}{$3.19 \times 10^{-4}$} & \multirow[t]{4}{*}{$9.39 \times 10^{-6}$} \\
\hline & 0.31504 & $1.8015 \times 10^{-4}$ & $2.4189 \times 10^{-6}$ & & \\
\hline & 0.41925 & $2.1841 \times 10^{-4}$ & $2.9029 \times 10^{-6}$ & & \\
\hline & 0.63009 & $2.820 \times 10^{-4}$ & $4.380 \times 10^{-6}$ & & \\
\hline \multirow{4}{*}{$t_{\mathrm{Bu}}$} & 0.20739 & $1.3495 \times 10^{-4}$ & $1.9918 \times 10^{-6}$ & \multirow[t]{4}{*}{$1.58 \times 10^{-4}$} & \multirow[t]{4}{*}{$1.04 \times 10^{-5}$} \\
\hline & 0.31349 & $1.4768 \times 10^{-4}$ & $2.2646 \times 10^{-6}$ & & \\
\hline & 0.41719 & $1.6432 \times 10^{-4}$ & $2.5447 \times 10^{-6}$ & & \\
\hline & 0.61975 & $2.0356 \times 10^{-4}$ & $4.4312 \times 10^{-6}$ & & \\
\hline \multirow{4}{*}{$t_{\mathrm{Bu}}$} & 0.16309 & $1.1865 \times 10^{-5}$ & $6.9298 \times 10^{-6}$ & \multirow[t]{4}{*}{$1.38 \times 10^{-4}$} & \multirow[t]{4}{*}{$1.20 \times 10^{-6}$} \\
\hline & 0.25962 & $2.5061 \times 10^{-5}$ & $8.4191 \times 10^{-6}$ & & \\
\hline & 0.3395 & $3.65 \times 10^{-5}$ & $8.4677 \times 10^{-6}$ & & \\
\hline & 0.40274 & $4.4893 \times 10^{-5}$ & $8.7878 \times 10^{-6}$ & & \\
\hline \multirow{4}{*}{$\mathrm{Me}$} & 0.14797 & $2.7011 \times 10^{-5}$ & $4.7255 \times 10^{-6}$ & \multirow[t]{4}{*}{$6.72 \times 10^{-5}$} & \multirow[t]{4}{*}{$2.14 \times 10^{-5}$} \\
\hline & 0.18959 & $3.4881 \times 10^{-5}$ & $5.3639 \times 10^{-6}$ & & \\
\hline & 0.28669 & $3.2151 \times 10^{-5}$ & $3.6806 \times 10^{-6}$ & & \\
\hline & 0.42541 & $4.7316 \times 10^{-5}$ & $3.6668 \times 10^{-6}$ & & \\
\hline
\end{tabular}


Table S3. Distribution of the phenolic compounds observed in the reaction mixtures obtained after the reaction of $\mathbf{1 a} / \mathbf{1 b} / \mathbf{3}$ with 2,4-DTBP at $65^{\circ} \mathrm{C}$ in acetonitrile.

\begin{tabular}{|l|c|c|c|}
\hline \multicolumn{1}{|c|}{ Additional reaction conditions } & $\mathbf{5}$ & $\mathbf{6}$ & (unreacted) \\
\hline $\mathbf{1 a}+2,4-\mathrm{DTBP}(1: 1)$ & 43 & 0 & 57 \\
\hline $\mathbf{1 a}+2,4-\mathrm{DTBP}(1: 10)$ & $15^{\mathrm{a}}$ & 0 & 85 \\
\hline $\mathbf{1 b}+2,4-\mathrm{DTBP}(1: 1)$ & trace & 0 & $>99$ \\
\hline $\mathbf{1 b}+2,4-\mathrm{DTBP}(1: 10)$ & trace & 0 & $>99$ \\
\hline $\mathbf{1 b}+2,4-\mathrm{DTBP}+\mathrm{NaNO}_{2}(1: 1: 10)$ & trace & 0 & $>99$ \\
\hline $\mathbf{3}+2,4-\mathrm{DTBP}(1: 1)$ & 31 & 8 & 61 \\
\hline $\mathbf{3}+2,4-\mathrm{DTBP}(1: 10)$ & 8 & 1 & 91 \\
\hline $\mathbf{3}+2,4-\mathrm{DTBP}+\mathrm{NaNO}_{2}(1: 1: 10)$ & 18 & 20 & 62 \\
\hline $\mathbf{B l a n k}: 2,4-\mathrm{DTBP}+\mathrm{NaNO}_{2}(1: 10)$ & trace & 0 & $>99$ \\
\hline
\end{tabular}

${ }^{\mathrm{a} C o p p e r(I I)-O H}$ complexes are known to react with substituted phenols to afford oxidatively coupled dimeric o, ${ }^{\prime}$-biphenols. ${ }^{57}$ 


\section{References}

(S1) (a) SHELXTL-PC, Vers. 5.10; 1998, Bruker-Analytical X-ray Services, Madison, WI. (b) G. M. Sheldrick, SHELX-97, Universität Göttingen, Göttingen, Germany.

(S2) SADABS; G. M. Sheldrick, 1996, based on the method described in R. H. Blessing, Acta Crystallogr. Sect. A, 1995, 51, 33-38.

(S3) CCDC Mercury Version 3.10; C. F. Macrae, P. R. Edgington, P. McCabe, E. Pidcock, G. P. Shields, R. Taylor, M. Towler and J. van de Streek, J. Appl. Cryst. 2006, $39,453-457$.

(S4) Chand, D. K.; Bharadwaj, P. K. Inorg. Chem. 1996, 35, 3380-3387.

(S5) Kundu, S.; Miceli, E.; Farquhar, E. R.; Ray, K. Dalton Trans. 2013, 43, 4264-4267.

(S6) Schopfer, M. P.; Mondal, B.; Lee, D.; Sarjeant, A. A. N.; Karlin, K. D. J. Am. Chem. Soc. 2009, 131, 11304-11305.

(S7) Diaz, D. E.; Bhadra, M.; Karlin, K. D. Inorg. Chem. 2019, 58, 13746-13750.

(S8) Lee, J. Y.; Peterson, R. L.; Ohkubo, K.; Garcia-Bosch, I.; Himes, R. A.; Woertink, J.; Moore, C. D.; Solomon, E. I.; Fukuzumi, S.; Karlin, K. D. J. Am. Chem. Soc. 2014, 136, 9925-9937.

(S9) Pignolet, L. H., Lewis, R. A. Holm, R. H. J. Am. Chem. Soc. 1971, 93, 360-371.

(S10) Cardenas, A. J. P., Abelman, R.; Warren, T. H. Chem. Commun. 2014, 50, 168170.

(S11) Fujii, S., Yoshimura, T. Coord. Chem. Rev. 2000, 198, 89-99.

(S12) Osako, T.; Taki, M.; Tachi, Y.; Itoh, S.; Ohkubo, K.; Fukuzumi, S. J. Am. Chem. Soc. 2003, 125, 11027-11033. 